\title{
Discovery of 12O-A Novel Oral Multi-Kinase Inhibitor for the Treatment of Solid Tumor
}

\author{
Yan Fan ${ }^{1,+} \mathbb{D}$, Zhi Huang ${ }^{1,+}$, Xiaoshuang Wang ${ }^{1}\left(\mathbb{D}\right.$, Yakun Ma ${ }^{1}$, Yongtao Li $^{1} \mathbb{D}^{\mathbb{D}}$, \\ Shengyong Yang ${ }^{2}$ and Yi Shi ${ }^{1, *}$ \\ 1 Department of Medicinal Chemistry, School of Medicine, Nankai University, 94 Weijin Road, \\ Tianjin 300071, China; yanfan@nankai.edu.cn (Y.F.); huangzhi@mail.nankai.edu.cn (Z.H.); \\ xswang@mail.nankai.edu.cn (X.W.); yakunma@nankai.edu.cn (Y.M.); liyt06198903@163.com (Y.L.) \\ 2 Medical Oncology, Cancer Center, State Key Laboratory of Biotherapy, West China Hospital, \\ Sichuan University, Chengdu 610064, China; yangsy@scu.edu.cn \\ * Correspondence: yishi@nankai.edu.cn \\ + These authors contributed equally to this work.
}

Received: 10 September 2020; Accepted: 3 November 2020; Published: 9 November 2020

\begin{abstract}
A novel series of pyrimidine-benzotriazole derivatives have been synthesized and evaluated for their anticancer activity against human solid tumor cell lines. The most promising molecule $\mathbf{1 2 O}$ was identified for its excellent antiproliferative activities, especially against the SiHa cell line with $\mathrm{IC}_{50}$ value as $0.009 \mu \mathrm{M}$. Kinase inhibition assay assessed $\mathbf{1 2 O}$ was a potential multi-kinase inhibitor, which possessed potent inhibitory activities against cyclin-dependent kinases (CDKs) and fms-like tyrosine kinase (FLT) with $\mathrm{IC}_{50}$ values in the nanomolar range. Molecular docking studies illustrated that the introduction of triazole moiety in $\mathbf{1 2 O}$ was critical for CDKs inhibition. In addition, $\mathbf{1 2 O}$ inhibited cancer cell proliferation, colony-formation, and cell cycle progression and provoked apoptotic death in vitro. In an $\mathrm{SiHa}$ xenograft mouse model, a once-daily dose of compound $\mathbf{1 2 O}$ at $20 \mathrm{mg} / \mathrm{kg}$ significantly suppressed the tumor growth without obvious toxicity. Taken together, $\mathbf{1 2 O}$ provided valuable guide for further structural optimization for CDKs and FLT inhibitors.
\end{abstract}

Keywords: CDK; FLT; inhibitor; cancer

\section{Introduction}

Cancer is an intricate and heterogeneous disease comprised of multistep and multigenetic processes. Many important genes aberrations severely disrupt the normal homoeostasis of cell growth and death [1]. Kinase inhibitors have been widely employed as molecularly targeted therapy drugs in clinical applications [2-4]. Individual molecular targets are often found to be less effective for treating complex disease, such as cancer, meaning that many single-target drugs cannot fully correct these diseases [5,6]. Multi-kinase inhibition is often a consequence of the simultaneous targeting of multiple pathways critical for tumor growth, including those contributing to proliferation, angiogenesis and apoptotic regulation. Compared with traditional agents, multi-kinase inhibitors that impact multiple targets simultaneously are better at controlling complex disease systems with superior efficacy, which are less prone to drug resistance, such as sorafenib, pazopanib, sunitinib, and dasatinib [7-10]. Therefore, rational drug discovery for more effective multi-target inhibitors may be necessary for cancer patients' therapy.

Among the variety of molecular targets for cancer therapy, we are particularly interested in cyclin-dependent kinases (CDKs). CDKs have important roles in several cellular processes that regulate the cell division, apoptosis, transcription, and differentiation. The subtypes $1-4$ and 6 of CDKs mainly mediate the cell cycle [11]. The CDK5 is associated with neuronal development and also 
plays a regulatory role in regulating various biological and pathological processes, including cancer progression [12]. The subtypes 7-9 of CDKs regulate transcription control [13]. Aberrations in CDKs and their partners have been observed in various tumors [14].

To date, multiple generations of $C D K$ drugs have been designed and reported. The third-generation CDK drugs targeting CDK4/6, palbociclib[15], ribociclib[16] and abemaciclib[17] have received significant attention. However, in clinical trials, palbociclib and ribociclib needed to combine with letrozole or tamoxifen for the treatment of cancer, which indicated a lack of sensitivity to CDK4/6 monotherapy $[18,19]$. Abemaciclib had additional kinase activities, such as CDK1, CDK2, CDK9, GSK-3a/b, CaM-kinase II and so on, all of which may be beneficial for anticancer activity [20]. Simultaneous inhibition of CDKs has been shown to increase antitumor activities compared with the inhibition of a single CDK alone [21-23]. In this paper, we discovered a lead compound $\mathbf{1 2 O}$ bearing 6-(pyrimidin-4-yl)-1H-benzo[d](1,2,3)triazole moiety as multi-target inhibitor against $\mathrm{CDKs}$ with $\mathrm{IC}_{50}$ values in the nanomolar range. Meanwhile, $\mathbf{1 2 O}$ has an impact on several important targets, such as FLT. Inhibition of these targets is likely to contribute to the substantial antitumor activity. $\mathbf{1 2 O}$ exhibited high potency against solid tumor, such as $\mathrm{SiHa}$ cells with an $\mathrm{IC}_{50}$ value of $0.009 \mu \mathrm{M}$. More importantly, $12 \mathrm{O}$ exhibited excellent in vivo efficacy in SiHa xenograft model with low toxicity. This work implied that compound $\mathbf{1 2 O}$ as a novel CDKs inhibitor deserved further research.

\section{Results and Discussion}

\subsection{Chemistry}

According to the literature [24], 1,2,3-triazole is one of the most fascinating nitrogen containing heterocycles, which has the ability to form effective non-covalent interactions with biological targets for discovery of potent anticancer agents. Many 1,2,3-triazole-containing compounds have immense importance in medicinal chemistry and exhibit anticancer activity. In order to discover novel active compounds to increase efficiencies against solid tumor, herein we introduced 1,2,3-triazole moiety and carried modifications based on 5J of our in-house compound library (Figure S1) [25]. Meanwhile, according to the structural characteristic of $\mathrm{CDK}$ inhibitor, we introduced a $\mathrm{CH}_{2}$ group to synthesize 12A-P (Figure S1).

The synthetic routes for all novel compounds are shown in Schemes 1 and 2. As shown in Scheme 1, commercial compound 4-bromo-2-fluoro-1-nitrobenzene (1) reacted with isopropylamine to give intermediate 2 , which underwent reduction reaction to provide compound 3 . Compound 3 was converted to 4 by closing the ring in the presence of conc. $\mathrm{HCl}$ and aq $\mathrm{NaNO}_{2}$. Then, 4 was heated with bis(pinacolato)diboronin to give 5, which yielded $\mathbf{6}$. As shown in Scheme 2, commercially available $\mathbf{7}$ reacted with aniline or substituted aniline to afford $\mathbf{8 A - P}$, which afforded $\mathbf{1 0 A - P}$. Then final compounds $12 \mathrm{~A}-\mathbf{P}$ were generated by a palladium catalyzed cross-coupling reaction of compounds 10A-P with compound 6.

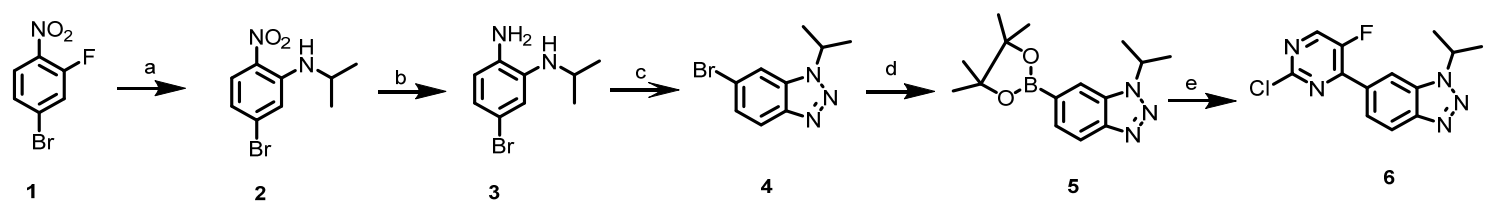

Scheme 1. Synthesis of the intermediate 6. (a) Isopropylamine, $\mathrm{K}_{2} \mathrm{CO}_{3}, \mathrm{DMF}, \mathrm{RT}, 96 \%$ yield; (b) $\mathrm{CH}_{3} \mathrm{COOH}, \mathrm{Fe}, 70{ }^{\circ} \mathrm{C}, 91 \%$ yield; (c) conc. $\mathrm{HCl}, \mathrm{NaNO}_{2}, 0{ }^{\circ} \mathrm{C}, 78 \%$ yield; (d) bis(pinacolato)diboron, $\mathrm{PdCl}_{2}$ (pddf), $\mathrm{KOAc}, 95^{\circ} \mathrm{C}, 67 \%$ yield; (e) 2,4-dichloro-5-fluoropyrimidine, $\mathrm{PdCl}_{2}$ (pddf), $\mathrm{NaHCO}_{3}$, $100{ }^{\circ} \mathrm{C}, 59 \%$ yield. 


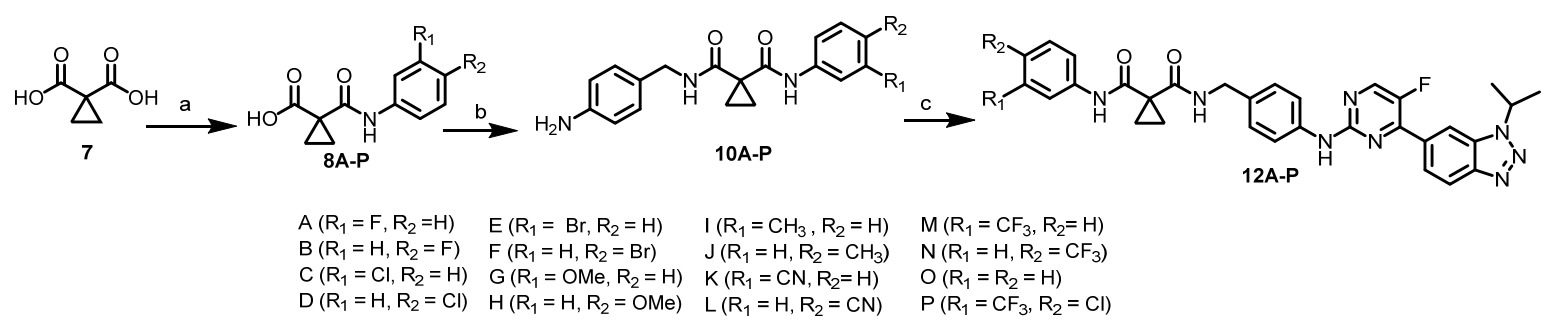

Scheme 2. Preparation of final compounds $12 \mathrm{~A}-\mathrm{P}$. (a) $\mathrm{SOCl}_{2}, \mathrm{Et}_{3} \mathrm{~N}$, THF, then aniline or substituted aniline, 55-84\% yield; (b) 4-(aminomethyl)aniline dihydrochloride, EDCI, HOBt, DIEA, RT, 50-86\% yield; (c) 6-(2-chloro-5-fluoropyrimidin-4-yl)-1-isopropyl-1H-benzo[d](1,2,3)triazole (6), $\mathrm{Pd}(\mathrm{AcO})_{2}$, BINAP, $\mathrm{Cs}_{2} \mathrm{CO}_{3}, 100{ }^{\circ} \mathrm{C}, 40-65 \%$ yield.

\subsection{Biological Evaluation}

\subsubsection{In Vitro Anticancer Screening}

In vitro anticancer screening of all newly synthesized compounds towards human solid tumor cells, cervical ( $\mathrm{SiHa}$ ) and ovarian (SKOV3) cancer cell lines, was carried out by standard CCK-8 assay with cisplatin as the positive control, as cisplatin is one of the most used chemotherapy drugs. The half maximal inhibitory concentration $\left(\mathrm{IC}_{50}\right)$ values of the tested compounds were listed in Table 1. Based on the observed results, most of the synthesized compounds exhibited good antiproliferative activity. Among them, molecule $\mathbf{1 2 0}$ was found to be the most active compound in this series of compounds. Compound $\mathbf{1 2 O}$ showed remarkable inhibitory effects against both cervical cancer cell line (SiHa) and ovarian cancer cell line (SKOV3) with $\mathrm{IC}_{50}$ values of $0.009 \mu \mathrm{M}$ and $0.029 \mu \mathrm{M}$, respectively, showing more activity than the standard drug cisplatin. The compound was further evaluated in a dose response study against a panel of solid tumor cells, including cervical cancer cell lines (SiHa and HeLa), ovarian cancer cell lines (SKOV3 and OVCAR-5), breast cancer cell lines (4T1 and MCF-7), lung cancer cell lines (A549 and H460) to test cytotoxic activity. The $\mathrm{IC}_{50}$ values were summarized in Table 2, including the cytotoxic activity of the cisplatin used as reference compound. 120 displayed obviously higher inhibition potency than positive control.

Table 1. In vitro cell growth inhibition $\mathrm{IC}_{50}$ values of compounds against cancer cell lines ${ }^{\mathrm{a}}$.

\begin{tabular}{|c|c|c|c|c|}
\hline \multirow{2}{*}{ Compounds } & \multirow{2}{*}{$\mathbf{R}_{\mathbf{1}}$} & \multirow{2}{*}{$\mathbf{R}_{2}$} & \multicolumn{2}{|c|}{ Cell Lines $\mathrm{IC}_{50}(\mu \mathrm{M})$} \\
\hline & & & SKOV3 & $\mathrm{SiHa}$ \\
\hline $12 \mathrm{~A}$ & $\mathrm{~F}$ & $\mathrm{H}$ & 0.531 & 0.035 \\
\hline 12B & $\mathrm{H}$ & $\mathrm{F}$ & 0.199 & 0.028 \\
\hline $12 \mathrm{C}$ & $\mathrm{Cl}$ & $\mathrm{H}$ & 0.459 & 0.068 \\
\hline $12 \mathrm{D}$ & $\mathrm{H}$ & $\mathrm{Cl}$ & 0.793 & 0.063 \\
\hline $12 \mathrm{E}$ & $\mathrm{Br}$ & $\mathrm{H}$ & 0.778 & 0.066 \\
\hline $12 \mathrm{~F}$ & $\mathrm{H}$ & $\mathrm{Br}$ & 0.706 & 0.128 \\
\hline $12 \mathrm{G}$ & $\mathrm{OMe}$ & $\mathrm{H}$ & 0.325 & 0.073 \\
\hline $12 \mathrm{H}$ & $\mathrm{H}$ & $\mathrm{OMe}$ & 0.312 & 0.080 \\
\hline $12 I$ & $\mathrm{CH}_{3}$ & $\mathrm{H}$ & 0.165 & 0.042 \\
\hline 12J & $\mathrm{H}$ & $\mathrm{CH}_{3}$ & 0.137 & 0.074 \\
\hline $12 \mathrm{~K}$ & $\mathrm{CN}$ & $\mathrm{H}$ & 0.108 & 0.083 \\
\hline $12 \mathrm{~L}$ & $\mathrm{H}$ & $\mathrm{CN}$ & 0.101 & 0.063 \\
\hline $12 \mathrm{M}$ & $\mathrm{CF}_{3}$ & $\mathrm{H}$ & 0.498 & 0.177 \\
\hline $12 N$ & $\mathrm{H}$ & $\mathrm{CF}_{3}$ & 0.427 & 0.160 \\
\hline $12 \mathrm{O}$ & $\mathrm{H}$ & $\mathrm{H}$ & 0.029 & 0.009 \\
\hline $12 P$ & $\mathrm{CF}_{3}$ & $\mathrm{Cl}$ & 0.915 & 0.231 \\
\hline Cisplatin & - & - & 5.358 & 4.907 \\
\hline
\end{tabular}

a The cytotoxic effect of compounds was assayed using CCK-8 assay with 72-h incubation. Data are from three independent experiments. 
Table 2. $\mathrm{IC}_{50}$ values of $\mathbf{1 2 O}$ against cancer cell lines ${ }^{\mathrm{a}}$.

\begin{tabular}{cccc}
\hline \multirow{2}{*}{ Cells } & \multirow{2}{*}{ Cell Type } & \multicolumn{2}{c}{ IC $_{\mathbf{5 0}}(\boldsymbol{\mu M})$} \\
\cline { 3 - 4 } & & $\mathbf{1 2 0}$ & Cisplatin \\
\hline SiHa & cervical cancer & 0.009 & 4.907 \\
HeLa & cervical cancer & 0.024 & 5.808 \\
MCF-7 & breast cancer & 0.010 & 7.156 \\
4T1 & breast cancer & 0.068 & 4.257 \\
OVCAR-5 & ovarian cancer & 0.052 & 1.244 \\
SKOV3 & ovarian cancer & 0.029 & 5.358 \\
A549 & lung cancer & 0.035 & 8.275 \\
H460 & lung cancer & 0.041 & $>10$ \\
\hline
\end{tabular}

a The cytotoxic effect of compounds was assayed using CCK-8 assay with 72-h incubation. Data are from three independent experiments.

The most active compound $\mathbf{1 2 O}$ with promising antiproliferative activities against the tested cell lines were subjected to further investigation for kinase inhibitory activities. Hit compound $5 \mathrm{~J}$ of our in-house compound library had a certain inhibitory activity against CDK4 $\left(\mathrm{IC}_{50}: 0.046 \mu \mathrm{M}\right)$ and VEGFR2 (vascular endothelial growth factor receptor, $\mathrm{IC}_{50}: 0.046 \mu \mathrm{M}$ ) and showed moderate activity in SiHa cells $\left(\mathrm{IC}_{50}: 0.050 \mu \mathrm{M}\right)$. Kinase inhibition assays with a fixed concentration of $1 \mu \mathrm{M}$ of compound $\mathbf{1 2 O}$ were carried out against the CDKs and VEGFR family kinases. The results were displayed in Table 3. Further, the $\mathrm{IC}_{50}$ values of targets with inhibitory activities over $90 \%$ in preliminary enzymatic assays were detected. As shown, $\mathbf{1 2 O}$ potently inhibited CDK2 $\left(\mathrm{IC}_{50}=0.005 \mu \mathrm{M}\right), \mathrm{CDK} 5\left(\mathrm{IC}_{50}=0.006 \mu \mathrm{M}\right)$, CDK9 $\left(\mathrm{IC}_{50}=0.009 \mu \mathrm{M}\right)$, and FLT4 (VEGFR3, $\left.\mathrm{IC}_{50}=0.068 \mu \mathrm{M}\right)$. It has been reported that CDK2 is critically associated with tumor growth in multiple cancer types [26]. CDK5 plays important roles in regulating cancer progression [12]. Inhibition of CDK9 leads to the inhibition of proliferation and the promotion of apoptosis in many cancers by reducing many proteins up-regulated [27]. Previous studies have shown that FLT4 has been shown to promote lymphangiogenesis, angiogenesis, and proliferation in cervical, breast and other cancers $[28,29]$. Therefore, inhibition of FLT4 signaling may have a therapeutic benefit in limiting subsequent tumor cell dissemination [30]. The inhibitory activity of $\mathbf{1 2 O}$ was also examined against PDGFR-related kinase because of their substantial sequence homology to the VEGFR family. $\mathbf{1 2 O}$ showed selectivity versus the remaining PDGFR-related members and a range of unrelated tyrosine and serine/threonine kinases except FLT3 $\left(\mathrm{IC}_{50}=0.024 \mu \mathrm{M}\right)($ Table 3). Most of the FLT3 inhibitors are applied for leukemia disease and some are used to treat solid tumors [22]. As reported, concurrent study of cell cycle arrest and angiogenesis inhibition was shown to be more effective due to synergy effects [31,32]. Thus, $\mathbf{1 2 O}$ is a novel multi-target kinase inhibitor against CDKs and FLT, all of which are intimately associated with the growth, survival, and metastasis in tumor cells. 
Table 3. Kinase inhibition profile of $\mathbf{1 2 O}$ against selected protein kinases ${ }^{\text {a }}$.

\begin{tabular}{|c|c|}
\hline Kinases & Inhibition $(\%)$ at $1 \mu \mathrm{M}$ \\
\hline \multicolumn{2}{|l|}{ CDK Family } \\
\hline CDK1/cyclinB(h) & $98\left(\mathrm{IC}_{50}=0.01 \mu \mathrm{M}\right)$ \\
\hline CDK2/cyclinA(h) & $99\left(\mathrm{IC}_{50}=0.005 \mu \mathrm{M}\right)$ \\
\hline CDK3/cyclinE(h) & 86 \\
\hline CDK4/cyclinD(h) & $91\left(\mathrm{IC}_{50}=0.157 \mu \mathrm{M}\right)$ \\
\hline CDK5/p25(h) & $99\left(\mathrm{IC}_{50}=0.006 \mu \mathrm{M}\right)$ \\
\hline CDK6/cyclinD3(h) & 74 \\
\hline CDK7/cyclinH/MAT1(h) & 53 \\
\hline CDK9/cyclin T1(h) & $100\left(\mathrm{IC}_{50}=0.009 \mu \mathrm{M}\right)$ \\
\hline \multicolumn{2}{|l|}{ VEGFR Family } \\
\hline KDR (VEGFR2) & 81 \\
\hline FLT1 (VEGFR1) & 50 \\
\hline FLT4 (VEGFR3) & $95\left(\mathrm{IC}_{50}=0.068 \mu \mathrm{M}\right)$ \\
\hline \multicolumn{2}{|l|}{ PDGFR Family } \\
\hline c-Kit(h) & 15 \\
\hline PDGFR-beta(h) & 12 \\
\hline PDGFR-alfa(h) & -1 \\
\hline FLT3(h) & $98\left(\mathrm{IC}_{50}=0.024 \mu \mathrm{M}\right)$ \\
\hline \multicolumn{2}{|c|}{ Representatives from other kinase families } \\
\hline FGFR1(h) & -23 \\
\hline $\operatorname{Src}(1-530)(h)$ & 46 \\
\hline $\mathrm{Abl}(\mathrm{h})$ & 31 \\
\hline
\end{tabular}

\subsubsection{Molecular Modeling of Compound $\mathbf{1 2 O}$}

As indicated above, $\mathbf{1 2 O}$ is a multi-target kinase inhibitor. Representative predicted binding modes of compound $\mathbf{1 2 O}$ in CDKs were carried out. As reported, [26,33] ASP145, LEU83 and PHE82 were key residues within the ATP binding pocket among CDK2. As shown in Figure 1a, 12O interacted with CDK2's hinge region via the hydrogen of the NH of LEU83 residue. The triazole group exploited the hydrophobic region close to the residue PHE82 to form a favorable $\pi-\pi$ interaction in CDK2. An additional hydrogen bond exists between the $\mathrm{NH}$ group of the compound $\mathbf{1 2 O}$ and ASP145 residue. As shown in Figure 1b, $\mathbf{1 2 O}$ tightly hydrogen-bonded with the kinase hinge regions in the ATP-binding pocket of CDK5. The triazole of $\mathbf{1 2 O}$ formed two hydrogen bonds with the LYS128 residue in CDK5. In addition, LYS33, GLY146, and TRY15 possessed a key role in positioning and binding of $\mathbf{1 2 O}$ through hydrogen bonds [34]. As shown in Figure 1c (PDB: 4BCF), an important hydrogen bond existed between the carbonyl group of the compound $\mathbf{1 2 O}$ and LYS151 residue of CDK9. The triazole of $\mathbf{1 2 O}$ forms a key hydrogen bond to the backbone ASP167 residue. Meanwhile, at the back of the ATP binding site, the triazole group exploited the hydrophobic region close to the gatekeeper residue PHE103 to form a favorable $\pi-\pi$ interaction in CDK9. Therefore, from Figure $1 \mathrm{a}-\mathrm{c}$, we can see that the great flexibility of $\mathbf{1 2 O}$ enabled CDKs to be effectively accommodated. The triazole substitute group was beneficial for the binding efficacy of $\mathbf{1 2 O}$ with kinase protein.

\subsection{3. $12 \mathrm{O}$ Inhibited Clonogenicity In Vitro}

Colony formation assay assesses the effect of a therapy on clonogenic survival which is one of the most important parameters of therapy efficacy in oncology. As the excellent inhibitory activity showed by $\mathbf{1 2 O}$ over $\mathrm{SiHa}$ cell line, we selected $\mathrm{SiHa}$ as representative model to detect the antitumor activities of $\mathbf{1 2 O}$ in vitro and in vivo. As shown in Figure 2, $\mathbf{1 2 O}$ dose-dependently decreased the formation of colonies in all the $\mathrm{SiHa}$ cell lines. Colony formation assays confirmed that $\mathbf{1 2 O}$ groups significantly reduced clonogenicity compared with the other treatments. We also performed colony formation assay in SKOV3 cells at concentrations according to $\mathrm{IC}_{50}$ values to confirm the result (Figure S3). 


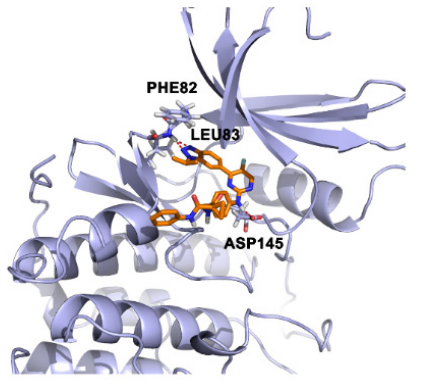

(a)

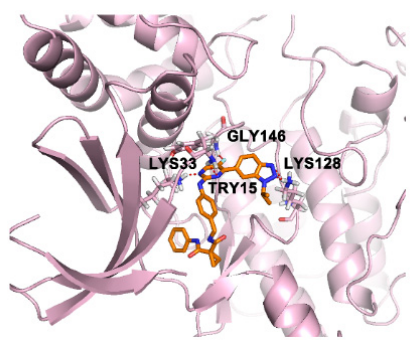

(b)

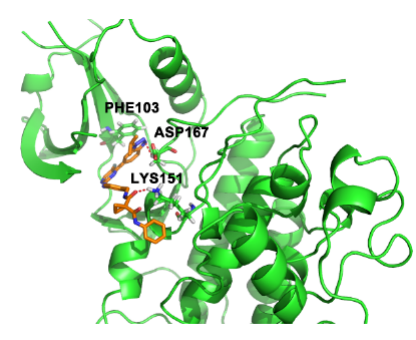

(c)

Figure 1. Predicted binding models of $\mathbf{1 2 O}$ (orange) in the active pocket of kinases. (a) Predicted binding modes of $\mathbf{1 2 O}$ in the ATP pocket of CDK2 (PDB entry: 1H1P). (b) Predicted binding mode of 120 with CDK5 (PDB entry: 1UNG). (c) Predicted binding mode of $\mathbf{1 2 O}$ within the active site of CDK9 (PDB entry: 4BCF). The red dashed lines represent the H-bond interaction.

Therefore, the respective predicted binding models explained the high potency of $\mathbf{1 2 O}$ toward CDKs. Analysis of molecular docking models showed a good accommodation of $\mathbf{1 2 O}$ onto the binding sites of CDKs, with the establishment of different contacts, such as hydrogen bonds, $\pi-\pi$ interactions, with the key residues of the investigated proteins.

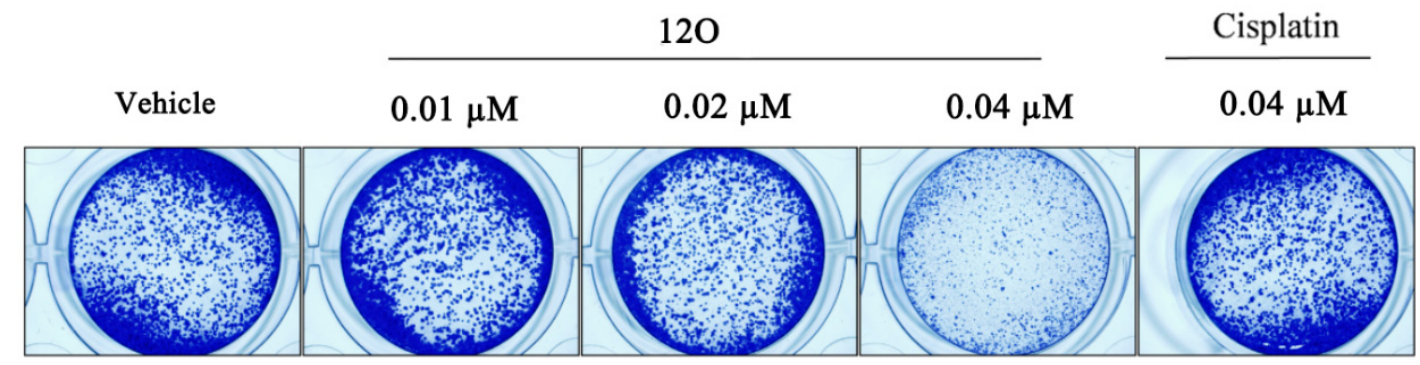

(a)

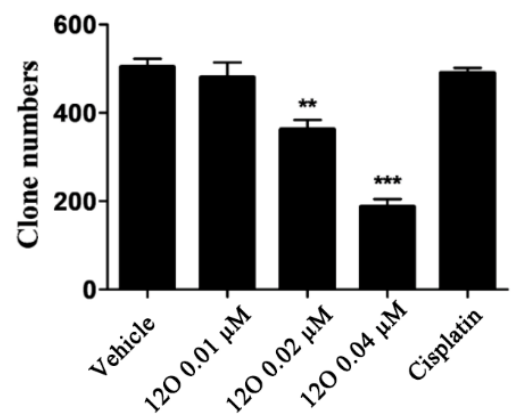

(b)

Figure 2. $12 \mathrm{O}$ effectively inhibited the proliferation of SiHa cells as determined by colony formation assay. (a) Representative pictures of colony formation assays. (b) Quantitative analysis of colony formation.2.2.4. $12 \mathrm{O}$ Induced the Cell Cycle Progress at G2/M Phase of Cancer Cells.

To understand how $\mathbf{1 2 O}$ inhibited cell proliferation, cell cycle analysis was performed. The effect of $\mathbf{1 2 O}$ on cell cycle distribution was assessed in the SiHa cell lines. The results indicated that $\mathbf{1 2 O}$ dose-dependently blocked the cell cycle at G2/M phase compared to the vehicle-treated cells (Figure 3). Of note, $12 \mathrm{O}$ at $0.04 \mu \mathrm{M}$ was able to increase the proportion of the cells in the G2/M phase from approximately $16.0 \pm 1.3 \%$ (DMSO) to $22.3 \pm 0.7 \%$, and decreased the corresponding fraction of the cells in the S phase from about $22.8 \pm 0.4 \%$ (DMSO) to $16.1 \pm 1.1 \%$ (Figure 3). Therefore, our results suggested that $\mathbf{1 2 O}$ inhibited cell proliferation by arresting cells in G2/M phase of the cell cycle. 


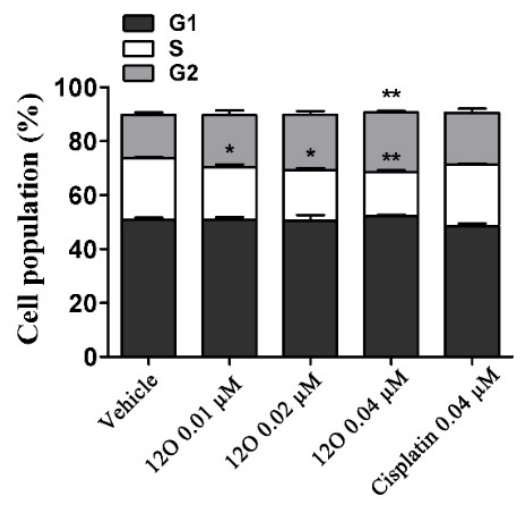

Figure 3. $12 \mathrm{O}$ induced G2 phase arrest in SiHa cancer cells. (G1 phase: preparation for DNA synthesis; $S$ phase: DNA synthesis; G2 phase: mitosis). Data are shown as the mean \pm s.d. ${ }^{*} p<0.05,{ }^{* *} p<0.01$.

\subsection{4. $12 \mathrm{O}$ Induced Cell Apoptosis In Vitro}

Subsequently, the effect of $\mathbf{1 2 O}$ on cell apoptosis was performed using Annexin V- FITV/PI staining. As shown in Figure 4, 120 treatment induced apoptosis of SiHa cells in a concentration-dependent manner. Compared with the cisplatin and vehicle condition, $\mathbf{1 2 O}$ increased the apoptotic cells (Q2 late apoptotic plus Q3 early apoptotic). This study illustrated that compound $\mathbf{1 2 O}$ could induce cell death via apoptosis.
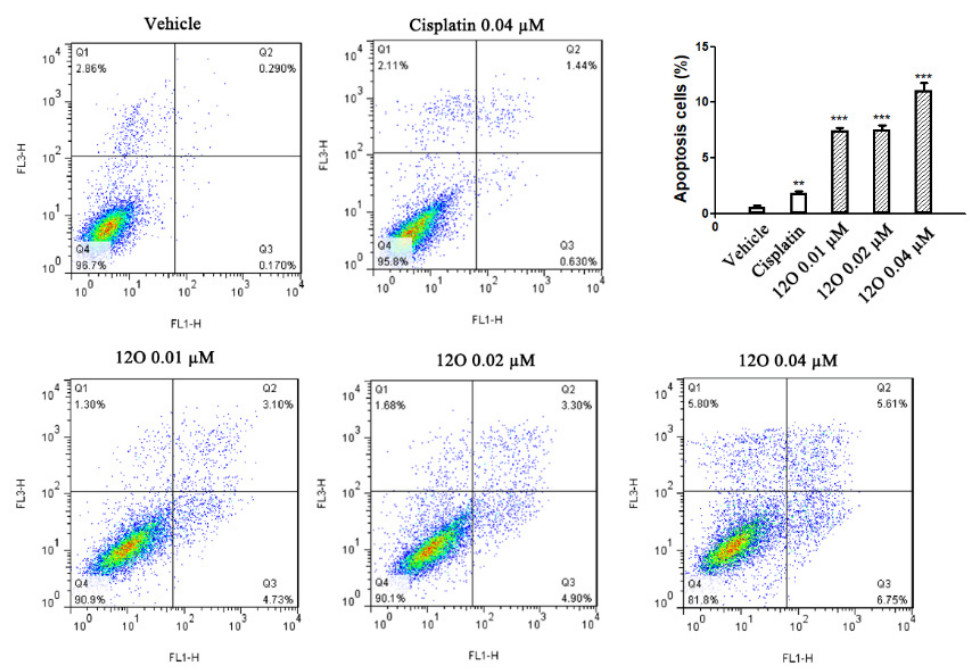

Figure 4. Compound $\mathbf{1 2 O}$ induced cell apoptosis of SiHa cell line in vitro. Data are shown as the mean \pm s.d. ${ }^{*} p<0.05,{ }^{* *} p<0.01,{ }^{* * *} p<0.001$.

\subsubsection{In Vivo Anti-Tumor Activity of $\mathbf{1 2 O}$}

Based on a desirable set of in vitro properties, $\mathbf{1 2 O}$ was finally selected for further in vivo evaluation. We proceeded to test the antitumor efficacy of $\mathbf{1 2 O}$ in SiHa xenograft mice. Animals were orally given three doses $\left(5,10\right.$, and $\left.20 \mathrm{mg} \mathrm{Kg}^{-1}\right)$ of $\mathbf{1 2 O}$, one dose $\left(20 \mathrm{mg} \mathrm{Kg}^{-1}\right)$ of cisplatin (positive control), or vehicle (control) every day. No obvious toxicity was observed in all the treated groups (Figure 5a). As shown in Figure 5, the growth of xenograft tumors was significantly inhibited by $\mathbf{1 2 O}$ in a dose-dependent manner. Tumor growth inhibitions of $51.25 \%, 65.52 \%, 79.29 \%$ were observed at doses of 5,10 , and $20 \mathrm{mg} / \mathrm{kg}$, respectively. In contrast, cisplatin $(20 \mathrm{mg} / \mathrm{kg})$ as the positive control was less potent (31.14\%) compared with $\mathbf{1 2 O}$ at the same dose. Of note, In Figure $5 c$, an obvious decrease in tumor size was also observed at the end of observation. The average tumor weight (Figure 5d) of the 12O-treated group was less than that of cisplatin. HE staining was further performed 
to identify the efficacy of $\mathbf{1 2 0}$ (Figure 5e). It was showed that the nuclei of tumor cells in vehicle controls were large and hyperchromatic, while the nuclei of 12O-treated tumor cells were pyknotic. HE staining results in tumor tissues treated with $\mathbf{1 2 O}$ further demonstrated the inhibition of tumor growth. Experiments in vivo demonstrated that $\mathbf{1 2 0}$ did have significant antitumor activity compared with cisplatin, which is used as a first-line chemotherapy drug against solid tumor in clinical settings. 120 as a novel multi-target kinase inhibitor effectively inhibited tumor growth of mice without obvious toxicity. Additional kinase activities of $\mathbf{1 2 0}$ intimately associated with the growth, survival, and metastasis in tumor cells, may contribute to the antitumor activity, but may also cause side effects. Multi-target kinase inhibitor extensively used in clinic cancer therapy, while hampered by associated adverse reactions and side-effect. Thus, further evidence is needed. An in-depth study of compound 120 is ongoing in our laboratory and will be reported in due course.

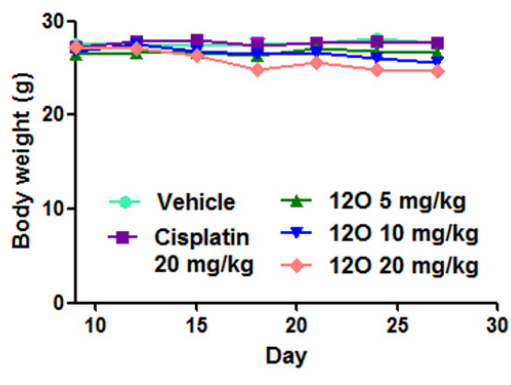

(a)

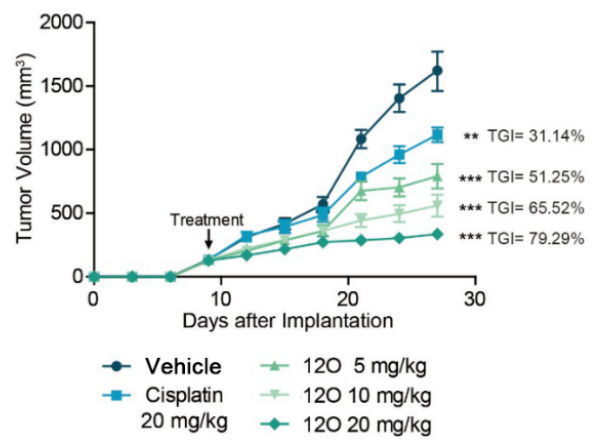

(c)

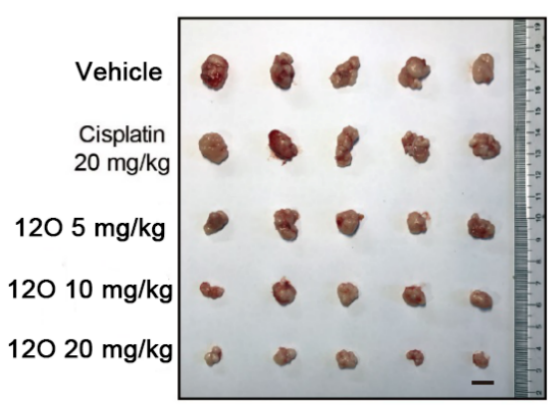

(b)

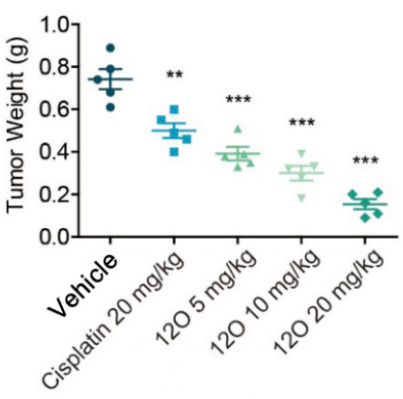

(d)

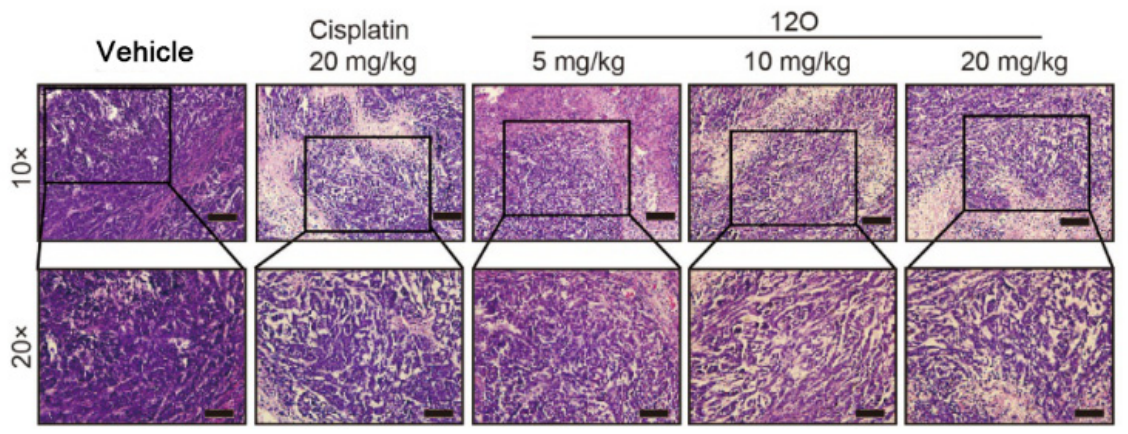

(e)

Figure 5. Pharmacodynamic profile of $\mathbf{1 2 O}$ in vivo. (a) Average body weight of established SiHa xenografts in female BALB/C nude mice ( $N=5$ per group, mean $\pm \mathrm{SD}$ ). (b) Photograph of excised tumors with respective mice at day 27 . Scale bar, $1 \mathrm{~cm}$. (c) Growth inhibitory effect of 12O, cisplatin or vehicle on xenograft tumor mice. (d) Tumor weight of mice in part B at day 27. (e) HE staining was performed. Scale bar, up: $200 \mu \mathrm{m}$; down: $100 \mu \mathrm{m}$. 


\section{Materials and Methods}

${ }^{1} \mathrm{H}$ NMR (400 MHz) and ${ }^{13} \mathrm{C}$ NMR (101 MHz) spectra were taken on a Bruker AV-400 MHz spectrometer, Bruker corporation, Karlsruhe, Germany. High Performance Liquid Chromatography (HPLC) was manufactured by Shimadzu, Kyoto, Japan. High-resolution mass spectra (HRMS) was manufactured by VG Instruments Ltd., London, UK. Flow cytometer was manufactured by Becton Dickinson (BD), San Jose, USA. Microscope was manufactured by Olympus, Tokyo, Japan. Cell incubator was manufactured by Thermo Fisher Scientific, Inc., Waltham, MA, USA. The ultra-pure water was supplied by a Milli-Q water purification system manufactured by EMD Millipore Corporation (Bedford, MA, USA).

\subsection{Chemistry}

\subsubsection{General Information}

The commercially obtained chemicals were used directly without further purification. Solvents were purified and distilled following the standard procedures. All the reactions were monitored by thin-layer chromatography (TLC). The NMR spectra were taken on a Bruker AV- $400 \mathrm{MHz}$ spectrometer $\left(400 \mathrm{MHz}\right.$ for ${ }^{1} \mathrm{H}$ and $101 \mathrm{MHz}$ for ${ }^{13} \mathrm{C}$ ) and chemical shifts were expressed in ppm downfield using tetramethylsilane as the internal standard. HRMSwere performed on a VG ZAB-HS mass spectrometer under electron spray ionization (ESI). All the derivatives for testing bioactivity were purified to $\geq 95 \%$ purity which was determined by HPLC analysis on a Shimadzu Prominence-i LC-2030C 3D system (column, InertSustain $\mathrm{C}_{18}, 4.6 \mathrm{~mm} \times 250 \mathrm{~mm}, 5 \mu \mathrm{M}$; mobile phase, gradient elution of methanol/ $\mathrm{H}_{2} \mathrm{O}(90: 10)$; low rate, $1.0 \mathrm{~mL} / \mathrm{min}$; UV wavelength, $190-800 \mathrm{~nm}$; temperature, $40^{\circ} \mathrm{C}$; injection volume, $\left.10 \mu \mathrm{L}\right)$.

\subsubsection{Synthesis of Intermediate Compound 6}

5-bromo-N-isopropyl-2-nitroaniline(2). An orange mixture of 4-bromo-2-fluoro-1 -nitrobenzene ( $4 \mathrm{~g}, 18.18 \mathrm{mmol})$, isopropylamine $(1.7 \mathrm{~mL}, 20 \mathrm{mmol})$ and $\mathrm{K}_{2} \mathrm{CO}_{3}(2.51 \mathrm{~g}, 36.36 \mathrm{mmol})$ in DMF $(40 \mathrm{~mL})$ was stirred at room temperature overnight. The resulting mixture was diluted with water and the mixture was extracted by ethyl acetate, and the combined organic layers were washed by water and brine, and dried by anhydrous magnesium sulfate. The solvent was evaporated, and the residue was purified by silica gel column chromatography to obtain $2(4.52 \mathrm{~g}, 96 \%)$ as a bright orange solid. ${ }^{1} \mathrm{H}$ NMR $\left(400 \mathrm{MHz}, \mathrm{DMSO}-d_{6}\right) \delta 8.08-7.77(\mathrm{~m}, 2 \mathrm{H}), 7.20(\mathrm{~d}, J=2.5 \mathrm{~Hz}, 1 \mathrm{H}), 6.76(\mathrm{dd}, J=9.1,2.3 \mathrm{~Hz}$, $1 \mathrm{H}), 4.08-3.77(\mathrm{~m}, 1 \mathrm{H}), 1.23(\mathrm{dd}, J=6.4,2.3 \mathrm{~Hz}, 6 \mathrm{H}) .{ }^{13} \mathrm{C}$ NMR $\left(101 \mathrm{MHz}, \mathrm{DMSO}-d_{6}\right) \delta 145.12,131.60$, $130.47,128.55,118.48,117.14,44.09,22.51$.

5-bromo-N ${ }^{1}$-isopropylbenzene-1,2-diamine(3). Compound $2(4 \mathrm{~g}, 15.4 \mathrm{mmol})$ was dissolved in $\mathrm{AcOH}$ $(100 \mathrm{~mL})$ and Fe powder $(8.6 \mathrm{~g}, 154 \mathrm{mmol}, 10$ equivalents) was added. The mixture was stirred at RT for $0.5 \mathrm{~h}$ and then heated at $70{ }^{\circ} \mathrm{C}$ for $3 \mathrm{~h}$. The suspension was basified with aqNaHCO 3 , diluted with $\mathrm{CH}_{2} \mathrm{Cl}_{2}(150 \mathrm{~mL})$, and filtered through celite. The filtrate was extracted with $\mathrm{CH}_{2} \mathrm{Cl}_{2}(2 \times 100 \mathrm{~mL})$ and the combined organic phases were dried $\left(\mathrm{K}_{2} \mathrm{CO}_{3}\right)$ and evaporated to furnish $3(3.2 \mathrm{~g}, 91 \%)$ as a dark solid. The crude product 3 was not subjected to further purification and was taken directly.

6-bromo-1-isopropyl-1H-benzo[d] $(1,2,3)$ triazole $(4)$. To a $0{ }^{\circ} \mathrm{C}$ mixture of the crude product 3 (3.2 $\mathrm{g}$, $14 \mathrm{mmol})$ in conc. $\mathrm{HCl}(40 \mathrm{~mL})$ was added $\mathrm{NaNO}_{2}(1.1 \mathrm{~g}, 15.4 \mathrm{mmol})$ in $\mathrm{H}_{2} \mathrm{O}(10 \mathrm{~mL})$. The mixture was allowed to warm to room temperature and was stirred for $1 \mathrm{~h}$. After recooling to $0{ }^{\circ} \mathrm{C}$, the mixture was treated with $6 \mathrm{~N} \mathrm{NaOH}$ until basic, the precipitate was then filtered, rinsed with $\mathrm{H}_{2} \mathrm{O}$ and dried to afford $4(2.62 \mathrm{~g}, 78 \%) .{ }^{1} \mathrm{H}$ NMR $\left(400 \mathrm{MHz}\right.$, DMSO- $\left.d_{6}\right) \delta 8.27(\mathrm{~d}, J=2.4 \mathrm{~Hz}, 1 \mathrm{H}), 7.98(\mathrm{dd}, J=8.9,2.3 \mathrm{~Hz}$, $1 \mathrm{H}), 7.48(\mathrm{dq}, J=8.8,1.6 \mathrm{~Hz}, 1 \mathrm{H}), 5.21(\mathrm{td}, J=6.7,2.3 \mathrm{~Hz}, 1 \mathrm{H}), 1.59(\mathrm{dd}, J=6.8,2.4 \mathrm{~Hz}, 6 \mathrm{H}) .{ }^{13} \mathrm{C} \mathrm{NMR}$ (101 MHz, DMSO-d 6 ) $\delta$ 147.32, 132.32, 129.26, 119.05, 117.79, 84.53, 83.27, 51.07, 25.27, 25.14, 22.75.

1-isopropyl-6-(4,4,5,5-tetramethyl-1,3,2-dioxaborolan-2-yl)-1H benzo[d](1,2,3) triazole(5). To a suspension of compound (4) ( $3 \mathrm{~g}, 12.5 \mathrm{mmol})$ in $50 \mathrm{~mL}$ 1,4-dioxane the following substances were added: bis(pinacolato)diboron ( $3.81 \mathrm{~g}, 15 \mathrm{mmol} 1.2$ equiv), $\mathrm{PdCl}_{2}$ (pddf) $(457 \mathrm{mg}, 0.625 \mathrm{mmol}$, 
0.05 equiv) and KOAc ( $4.3 \mathrm{~g}, 43.8 \mathrm{mmol}, 3.5 \mathrm{equiv})$ and the flask was purged with $\mathrm{N}_{2}$. Then the flask was sealed and the mixture was heated for $12 \mathrm{~h}$ at $95^{\circ} \mathrm{C}$. The reaction was cooled to RT, the solvent was removed under reduced pressure, and the residue was purified by silica gel column chromatography to obtain 5 (2.4 g, 67\%). ${ }^{1} \mathrm{H}$ NMR $\left(400 \mathrm{MHz}, \mathrm{DMSO}-d_{6}\right) \delta 8.17(\mathrm{~s}, 1 \mathrm{H}), 8.01(\mathrm{~d}, J=8.3 \mathrm{~Hz}, 1 \mathrm{H}), 7.64$ $(\mathrm{d}, J=8.4 \mathrm{~Hz}, 1 \mathrm{H}), 5.33(\mathrm{p}, J=6.7 \mathrm{~Hz}, 1 \mathrm{H}), 1.61(\mathrm{~d}, J=6.7 \mathrm{~Hz}, 6 \mathrm{H}), 1.32(\mathrm{~s}, 12 \mathrm{H}) .{ }^{13} \mathrm{C} \mathrm{NMR}(101 \mathrm{MHz}$, DMSO-d $\left.{ }_{6}\right) \delta 147.32,132.32,129.26,119.05,117.79,83.27,51.07,25.14,22.75$.

6-(2-chloro-5-fluoropyrimidin-4-yl)-1-isopropyl-1H-benzo[d] $(1,2,3)$ triazole(6). To a suspension of compound (5) (2 g, $7 \mathrm{mmol})$ in $50 \mathrm{~mL} \mathrm{1,4-dioxane} \mathrm{and} 5 \mathrm{~mL} \mathrm{H}_{2} \mathrm{O}$, the following substances were added: 2,4-dichloro-5-fluoropyrimidine ( $2.3 \mathrm{~g}$, $14 \mathrm{mmol}, 2$ equiv), $\mathrm{PdCl}_{2}$ (pddf) (512 mg, $0.7 \mathrm{mmol}, 0.1$ equiv) and $\mathrm{NaHCO}_{3}\left(1.8 \mathrm{~g}, 21 \mathrm{mmol}, 3\right.$ equiv) and the flask was purged with $\mathrm{N}_{2}$. Then the flask was sealed and the mixture was heated for $12 \mathrm{~h}$ at $100{ }^{\circ} \mathrm{C}$. The reaction was cooled to RT, the solvent was removed under reduced pressure, and the residue was purified by silica gel column chromatography to obtain 6 $(1.2 \mathrm{~g}, 59 \%) .{ }^{1} \mathrm{H}$ NMR $\left.\left(400 \mathrm{MHz}, \mathrm{DMSO}_{-}\right)_{6}\right) 8.98(\mathrm{~d}, J=3.0 \mathrm{~Hz}, 1 \mathrm{H}), 8.46(\mathrm{~s}, 1 \mathrm{H}), 8.16(\mathrm{~d}, J=8.7 \mathrm{~Hz}$, $1 \mathrm{H}), 8.03-7.82(\mathrm{~m}, 1 \mathrm{H}), 5.34(\mathrm{p}, J=6.7 \mathrm{~Hz}, 1 \mathrm{H}), 1.64(\mathrm{~d}, J=6.6 \mathrm{~Hz}, 6 \mathrm{H}) .{ }^{13} \mathrm{C}$ NMR $\left(101 \mathrm{MHz}, \mathrm{DMSO}-d_{6}\right)$ $\delta 155.49(\mathrm{~d}, J=265.4 \mathrm{~Hz}), 154.70(\mathrm{~d}, J=3.6 \mathrm{~Hz}), 153.95(\mathrm{~d}, J=10.1 \mathrm{~Hz}), 150.48(\mathrm{~d}, J=26.8 \mathrm{~Hz}), 146.76$, 132.36, $130.17(\mathrm{~d}, J=5.1 \mathrm{~Hz}), 124.57(\mathrm{~d}, J=5.8 \mathrm{~Hz}), 120.16,112.80(\mathrm{~d}, J=7.3 \mathrm{~Hz}), 51.58,22.57$.

\subsubsection{General Procedure for the Preparation of 8A-P}

To a stirred solution of cyclopropane-1,1-dicarboxylic acid (7) (13.01 g, $100 \mathrm{mmol}$ ) in isopropyl acetate $(150 \mathrm{~mL})$ at $0{ }^{\circ} \mathrm{C}$, thionyl chloride $(12.5 \mathrm{~g}, 105 \mathrm{mmol})$ was added dropwise. After addition, the resulting mixture was stirred at room temperature and stirred for $6 \mathrm{~h}$. The resulting mixture was then treated with a solution of aniline or substituted aniline $(110 \mathrm{mmol})$ and triethylamine $(110 \mathrm{mmol})$ in isopropyl acetate $(40 \mathrm{~mL})$ over $1 \mathrm{~h}$. After stirring for $2 \mathrm{~h}$, the resulting mixture was added to ethyl acetate $(500 \mathrm{~mL})$. The solvent was washed by $1 \mathrm{~N} \mathrm{HCl}$ solution and brine. The organic phase was dried over $\mathrm{MgSO} 4$, evaporated and the residue treated with heptane (200 $\mathrm{mL})$. The product slurry was stirred for $0.5 \mathrm{~h}$, filtered and dried under vacuum to obtain product.

1-((3-fluorophenyl)carbamoyl)cyclopropane-1-carboxylic acid (8A). White solid $(76 \%),{ }^{1} \mathrm{H}$ NMR $\left(400 \mathrm{MHz}, \mathrm{DMSO}-d_{6}\right) \delta 13.12(\mathrm{~s}, 1 \mathrm{H}), 10.73(\mathrm{~s}, 1 \mathrm{H}), 7.61(\mathrm{dt}, J=11.3,2.0 \mathrm{~Hz}, 1 \mathrm{H}), 7.41-7.27(\mathrm{~m}, 2 \mathrm{H})$, $6.88(\mathrm{ddt}, J=9.1,6.7,2.7 \mathrm{~Hz}, 1 \mathrm{H}), 1.41(\mathrm{~s}, 4 \mathrm{H})$.

1-((4-fluorophenyl)carbamoyl)cyclopropane-1-carboxylic acid (8B). White solid (67\%), ${ }^{1} \mathrm{H}$ NMR $\left(400 \mathrm{MHz}, \mathrm{DMSO}-d_{6}\right) \delta 13.11(\mathrm{~s}, 1 \mathrm{H}), 10.81-10.50(\mathrm{~m}, 1 \mathrm{H}), 7.63(\mathrm{dd}, J=8.9,5.0 \mathrm{~Hz}, 2 \mathrm{H}), 7.13(\mathrm{tt}, J=8.9$, $3.0 \mathrm{~Hz}, 2 \mathrm{H}), 1.54-1.30(\mathrm{~m}, 4 \mathrm{H})$.

1-((3-chlorophenyl)carbamoyl)cyclopropane-1-carboxylic acid (8C). White solid (81\%), ${ }^{1} \mathrm{H}$ NMR $\left(400 \mathrm{MHz}, \mathrm{DMSO}-d_{6}\right) \delta 13.12(\mathrm{~s}, 1 \mathrm{H}), 10.70(\mathrm{~s}, 1 \mathrm{H}), 7.83(\mathrm{t}, J=1.9 \mathrm{~Hz}, 1 \mathrm{H}), 7.46(\mathrm{~d}, J=8.2 \mathrm{~Hz}$, $1 \mathrm{H}), 7.32(\mathrm{td}, J=8.1,1.5 \mathrm{~Hz}, 1 \mathrm{H}), 7.10(\mathrm{dd}, J=7.9,2.1 \mathrm{~Hz}, 1 \mathrm{H}), 1.42(\mathrm{~s}, 4 \mathrm{H}) ;{ }^{13} \mathrm{C} \mathrm{NMR}(101 \mathrm{MHz}$, DMSO- $\left.d_{6}\right) \delta 173.52,167.03,140.20,133.04,130.33,123.03,118.79,117.69,28.87,16.98$.

1-((4-chlorophenyl)carbamoyl)cyclopropane-1-carboxylic acid (8D). White solid (55\%), ${ }^{1} \mathrm{H}$ NMR $\left(400 \mathrm{MHz}, \mathrm{DMSO}-d_{6}\right) \delta 13.10(\mathrm{~s}, 1 \mathrm{H}), 10.65$ (s, 1H), 7.71-7.54 (m, 2H), 7.49-7.23 (m, 2H), $1.41(\mathrm{~s}, 4 \mathrm{H})$; ${ }^{13} \mathrm{C}$ NMR $\left(101 \mathrm{MHz}\right.$, DMSO- $\left.d_{6}\right) \delta 173.60,166.80,137.75,128.56,126.87,120.85,28.80,16.95$.

1-((3-bromophenyl)carbamoyl)cyclopropane-1-carboxylic acid (8E). White solid (76\%), ${ }^{1} \mathrm{H}$ NMR $\left(400 \mathrm{MHz}, \mathrm{DMSO}-d_{6}\right) \delta 13.12(\mathrm{~s}, 1 \mathrm{H}), 10.69(\mathrm{~s}, 1 \mathrm{H}), 7.97(\mathrm{t}, J=2.0 \mathrm{~Hz}, 1 \mathrm{H}), 7.50(\mathrm{dt}, J=7.5,1.9$ $\mathrm{Hz}, 1 \mathrm{H}), 7.39-7.15$ (m, 2H), $1.42(\mathrm{~s}, 4 \mathrm{H}) ;{ }^{13} \mathrm{C}$ NMR (101 MHz, DMSO-d $\left.{ }_{6}\right) \delta 174.03,167.51,140.83,131.13$, $126.43,122.14,122.01,118.57,29.38,17.50$.

1-((4-bromophenyl)carbamoyl)cyclopropane-1-carboxylic acid $(\mathbf{8 F})$. White solid $(84 \%),{ }^{1} \mathrm{H}$ NMR $\left(400 \mathrm{MHz}, \mathrm{DMSO}-d_{6}\right) \delta 13.13(\mathrm{~s}, 1 \mathrm{H}), 10.70$ (s, 1H), 7.64-7.55 (m, 2H), 7.51-7.41 (m, 2H), 1.43 (s, 4H); ${ }^{13} \mathrm{C}$ NMR (101 MHz, DMSO- $\left.d_{6}\right) \delta 174.22,167.32,138.61,131.95,121.73,115.43,29.15,17.70$.

1-((3-methoxyphenyl)carbamoyl)cyclopropane-1-carboxylic acid (8G). White solid $(65 \%),{ }^{1} \mathrm{H}$ NMR $\left(400 \mathrm{MHz}, \mathrm{DMSO}-d_{6}\right) \delta 13.09(\mathrm{~s}, 1 \mathrm{H}), 10.62(\mathrm{~s}, 1 \mathrm{H}), 7.33(\mathrm{t}, J=2.1 \mathrm{~Hz}, 1 \mathrm{H}), 7.20(\mathrm{t}, J=8.1 \mathrm{~Hz}, 1 \mathrm{H})$, $7.13(\mathrm{dt}, J=8.2,1.3 \mathrm{~Hz}, 1 \mathrm{H}), 6.63(\mathrm{ddd}, J=8.1,2.5,1.0 \mathrm{~Hz}, 1 \mathrm{H}), 3.72(\mathrm{~s}, 3 \mathrm{H}), 1.43(\mathrm{~s}, 4 \mathrm{H}) ;{ }^{13} \mathrm{C} \mathrm{NMR}$ $\left(101 \mathrm{MHz}, \mathrm{DMSO}-d_{6}\right) \delta 174.40,167.20,159.99,140.42,129.95,112.05,109.40,105.50,55.40,29.01,17.77$. 
1-((4-methoxyphenyl)carbamoyl)cyclopropane-1-carboxylic acid (8H). Off-white solid (70\%), ${ }^{1} \mathrm{H}$ NMR (400 MHz, DMSO-d 6 ) $\delta 10.49$ (s, 1H), 7.60-7.31 (m, 2H), 7.12-6.68 (m, 2H), $3.71(\mathrm{~s}, 3 \mathrm{H}), 1.42(\mathrm{~s}, 4 \mathrm{H})$;

${ }^{13} \mathrm{C}$ NMR $\left(101 \mathrm{MHz}\right.$, DMSO-d $\left.{ }_{6}\right) \delta 174.56,166.77,155.78,132.36,121.41,114.27,55.57,28.59,17.81$.

1-(m-tolylcarbamoyl)cyclopropane-1-carboxylic acid (8I). White solid (75\%), ${ }^{1} \mathrm{H}$ NMR (400 $\mathrm{MHz}$, DMSO- $\left.d_{6}\right) \delta 13.14(\mathrm{~s}, 1 \mathrm{H}), 10.58(\mathrm{~s}, 1 \mathrm{H}), 7.52-7.31(\mathrm{~m}, 2 \mathrm{H}), 7.17(\mathrm{t}, J=7.8 \mathrm{~Hz}, 1 \mathrm{H}), 6.87(\mathrm{~d}, J=7.4 \mathrm{~Hz}$, $1 \mathrm{H}), 2.27(\mathrm{~s}, 3 \mathrm{H}), 1.42(\mathrm{~s}, 4 \mathrm{H})$.

1-(p-tolylcarbamoyl)cyclopropane-1-carboxylic acid (8J). White solid (79\%), ${ }^{1} \mathrm{H}$ NMR (400 MHz, DMSO- $\left.d_{6}\right) \delta 13.11(\mathrm{~s}, 1 \mathrm{H}), 10.54(\mathrm{~s}, 1 \mathrm{H}), 7.60-7.36(\mathrm{~m}, 2 \mathrm{H}), 7.20-6.99(\mathrm{~m}, 2 \mathrm{H}), 2.25(\mathrm{~s}, 3 \mathrm{H}), 1.42(\mathrm{~s}, 4 \mathrm{H})$.

1-((3-cyanophenyl)carbamoyl)cyclopropane-1-carboxylic acid (8K). White solid (79\%), ${ }^{1} \mathrm{H}$ NMR $\left(400 \mathrm{MHz}, \mathrm{DMSO}-d_{6}\right) \delta 13.15(\mathrm{~s}, 1 \mathrm{H}), 10.84(\mathrm{~s}, 1 \mathrm{H}), 8.11(\mathrm{q}, J=1.3 \mathrm{~Hz}, 1 \mathrm{H}), 7.84(\mathrm{ddd}, J=6.0$, 3.3, $2.2 \mathrm{~Hz}, 1 \mathrm{H}), 7.69-7.39$ (m, 2H), $1.43(\mathrm{~s}, 4 \mathrm{H}) ;{ }^{13} \mathrm{C}$ NMR $(101 \mathrm{MHz}$, DMSO-d 6 ) $\delta 173.88,167.82,140.06$, $130.65,127.37,124.38,122.49,119.12,112.03,29.46,17.44$.

1-((4-cyanophenyl)carbamoyl)cyclopropane-1-carboxylic acid (8L). Yellow solid (79\%), ${ }^{1} \mathrm{H}$ NMR $\left(400 \mathrm{MHz}, \mathrm{DMSO}-d_{6}\right) \delta 13.13$ (s, 1H), 10.90 (s, 1H), 7.90-7.62 (m, 4H), $1.42(\mathrm{~s}, 4 \mathrm{H}) ;{ }^{13} \mathrm{C} \mathrm{NMR}(101 \mathrm{MHz}$, DMSO- $\left.d_{6}\right) \delta 173.76,167.90,143.48,133.70,119.78,119.49,105.53,29.85,17.29$.

1-((3-(trifluoromethyl)phenyl)carbamoyl)cyclopropane-1-carboxylic acid (8M). White solid (81\%), ${ }^{1} \mathrm{H}$ NMR (400 MHz, DMSO-d 6 ) $\delta 13.13(\mathrm{~s}, 1 \mathrm{H}), 10.83(\mathrm{~s}, 1 \mathrm{H}), 8.13(\mathrm{t}, J=1.9 \mathrm{~Hz}, 1 \mathrm{H}), 7.95-7.72(\mathrm{~m}, 1 \mathrm{H})$, $7.53(\mathrm{t}, J=8.0 \mathrm{~Hz}, 1 \mathrm{H}), 7.46-7.30(\mathrm{~m}, 1 \mathrm{H}), 1.43(\mathrm{~s}, 4 \mathrm{H}) ;{ }^{13} \mathrm{C}$ NMR $\left(101 \mathrm{MHz}, \mathrm{DMSO}-d_{6}\right) \delta 173.92,167.75$, $140.04,130.39,130.34,130.08,129.77,129.45,128.60,125.89,123.33,123.18,120.13,120.09,115.89,115.85$, $29.49,17.34$.

1-((4-(trifluoromethyl)phenyl)carbamoyl)cyclopropane-1-carboxylic acid (8N). Yellow solid (82\%), ${ }^{1} \mathrm{H}$ NMR $\left(400 \mathrm{MHz}\right.$, DMSO- $\left.d_{6}\right) \delta 12.95(\mathrm{~s}, 1 \mathrm{H}), 10.91(\mathrm{~s}, 1 \mathrm{H}), 7.82(\mathrm{~d}, J=8.5 \mathrm{~Hz}, 2 \mathrm{H}), 7.65(\mathrm{~d}, J=8.5 \mathrm{~Hz}$, 2H), $1.44(\mathrm{~s}, 4 \mathrm{H}) ;{ }^{13} \mathrm{C}$ NMR $\left(101 \mathrm{MHz}, \mathrm{DMSO}-d_{6}\right) \delta 174.04,167.78,142.80,126.48,126.45,126.41,126.13$, $124.03,123.71,123.43,119.65,29.44,17.55$.

1-(phenylcarbamoyl)cyclopropane-1-carboxylic acid (8O). White solid (66\%), ${ }^{1} \mathrm{H}$ NMR (400 $\mathrm{MHz}$, DMSO-d $)_{6} \delta 13.10(\mathrm{~s}, 1 \mathrm{H}), 10.60(\mathrm{~s}, 1 \mathrm{H}), 7.63-7.54(\mathrm{~m}, 2 \mathrm{H}), 7.40-7.27(\mathrm{~m}, 2 \mathrm{H}), 7.11-6.99(\mathrm{~m}, 1 \mathrm{H})$, $1.42(\mathrm{~s}, 4 \mathrm{H})$.

1-((4-chloro-3-(trifluoromethyl)phenyl)carbamoyl)cyclopropane-1-carboxylic acid (8P). White solid (67\%), ${ }^{1} \mathrm{H}$ NMR $\left(400 \mathrm{MHz}, \mathrm{DMSO}-\mathrm{d}_{6}\right) \delta 13.13(\mathrm{~s}, 1 \mathrm{H}), 10.88(\mathrm{~s}, 1 \mathrm{H}), 8.20(\mathrm{~d}, J=2.3 \mathrm{~Hz}, 1 \mathrm{H}), 7.85(\mathrm{~d}, J=8.8 \mathrm{~Hz}$, $1 \mathrm{H}), 7.71-7.43(\mathrm{~m}, 1 \mathrm{H}), 1.42(\mathrm{~s}, 4 \mathrm{H}) ;{ }^{13} \mathrm{C} \mathrm{NMR}\left(101 \mathrm{MHz}, \mathrm{DMSO}-d_{6}\right) \delta 173.24,167.32,138.23,131.95$, $131.91,126.82,126.51,124.01,121.28,117.97,117.91,29.02,16.75$.

\subsubsection{General Procedure for the Preparation of 10A-P}

To a two-necked flask, compound 8A-P (30 mmol), 4-(aminomethyl)aniline dihydrochloride (30 mmol), EDCI (45 mmol), HOBt (36 mmol), DIEA (120 mmol) and DMF (30 mL) were charged. The mixture was stirred at room temperature for $12 \mathrm{~h}$, then quenched by water. The mixture was extracted by ethyl acetate, and the combined organic layers were washed by saturated aqueous $\mathrm{NaHCO}_{3}$ solution, water and brine, dried by anhydrous magnesium sulfate. The solvent was evaporated, and the residue was purified by silica gel column chromatography.

$N$-(4-(aminomethyl)phenyl)-N-(3-fluorophenyl)cyclopropane-1,1-dicarboxamide(10A). Brown solid (69\%), ${ }^{1} \mathrm{H}$ NMR (400 MHz, DMSO-d $) \delta 10.91(\mathrm{~s}, 1 \mathrm{H}), 8.27(\mathrm{~s}, 1 \mathrm{H}), 7.63(\mathrm{~d}, J=11.6 \mathrm{~Hz}, 1 \mathrm{H})$, $7.32(\mathrm{~d}, J=4.4 \mathrm{~Hz}, 2 \mathrm{H}), 6.91(\mathrm{dd}, J=21.6,5.2 \mathrm{~Hz}, 3 \mathrm{H}), 6.51(\mathrm{~d}, J=8.1 \mathrm{~Hz}, 2 \mathrm{H}), 4.96(\mathrm{~s}, 2 \mathrm{H})$, $4.15(\mathrm{~d}, J=5.8 \mathrm{~Hz}, 2 \mathrm{H}), 1.39(\mathrm{~d}, J=3.1 \mathrm{~Hz}, 4 \mathrm{H}) .{ }^{13} \mathrm{C}$ NMR $\left(101 \mathrm{MHz}\right.$, DMSO- $\left.\mathrm{d}_{6}\right) \delta 170.18,168.48,162.05$ $(\mathrm{d}, J=240.9 \mathrm{~Hz}), 147.48,140.40(\mathrm{~d}, J=11.0 \mathrm{~Hz}), 130.14(\mathrm{~d}, J=9.6 \mathrm{~Hz}), 128.15,126.10,115.54,113.68$, $109.85(\mathrm{~d}, J=20.9 \mathrm{~Hz}), 106.67(\mathrm{~d}, J=26.2 \mathrm{~Hz}), 42.35,29.52,15.92$.

$\mathrm{N}$-(4-(aminomethyl)phenyl)-N-(4-fluorophenyl)cyclopropane-1,1-dicarboxamide (10B). Brown solid $(78 \%),{ }_{1}^{1} \mathrm{H}$ NMR (400 MHz, DMSO-d 6$) \delta 10.69(\mathrm{~s}, 1 \mathrm{H}), 8.31(\mathrm{~d}, J=5.9 \mathrm{~Hz}, 1 \mathrm{H}), 7.61(\mathrm{dd}, J=8.8$, $5.0 \mathrm{~Hz}, 2 \mathrm{H}), 7.13(\mathrm{t}, J=8.7 \mathrm{~Hz}, 2 \mathrm{H}), 6.94(\mathrm{~d}, J=8.0 \mathrm{~Hz}, 2 \mathrm{H}), 6.51(\mathrm{~d}, J=8.0 \mathrm{~Hz}, 2 \mathrm{H}), 4.95(\mathrm{~s}, 2 \mathrm{H})$, $4.16(\mathrm{~d}, J=5.8 \mathrm{~Hz}, 2 \mathrm{H}), 1.39(\mathrm{~d}, J=6.0 \mathrm{~Hz}, 4 \mathrm{H}) .{ }^{13} \mathrm{C}$ NMR $\left(101 \mathrm{MHz}, \mathrm{DMSO}-\mathrm{d}_{6}\right) \delta 170.24,168.24,158.15$ 
$(\mathrm{d}, J=240.5 \mathrm{~Hz}), 147.50,135.02,128.16,126.10,121.81(\mathrm{~d}, J=7.7 \mathrm{~Hz}), 115.10(\mathrm{~d}, J=21.9 \mathrm{~Hz}), 113.69$, $42.35,29.24,15.84$.

$\mathrm{N}$-(4-(aminomethyl)phenyl)- $\mathrm{N}$-(3-chlorophenyl)cyclopropane-1,1-dicarboxamide (10C). Brown solid $(65 \%),{ }_{1}^{1} \mathrm{H}$ NMR $\left(400 \mathrm{MHz}, \mathrm{DMSO}-d_{6}\right) \delta 10.83(\mathrm{~s}, 1 \mathrm{H}), 8.28(\mathrm{t}, J=5.8 \mathrm{~Hz}, 1 \mathrm{H}), 7.85(\mathrm{t}, J=2.1 \mathrm{~Hz}$, $1 \mathrm{H}), 7.45(\mathrm{ddd}, J=8.2,2.1,1.0 \mathrm{~Hz}, 1 \mathrm{H}), 7.32(\mathrm{t}, J=8.1 \mathrm{~Hz}, 1 \mathrm{H}), 7.11(\mathrm{ddd}, J=7.9,2.1,1.0 \mathrm{~Hz}, 1 \mathrm{H})$, 6.95-6.88 (m, 2H), 6.52-6.46 (m, 2H), $4.95(\mathrm{~s}, 2 \mathrm{H}), 4.15(\mathrm{~d}, J=5.8 \mathrm{~Hz}, 2 \mathrm{H}), 1.38(\mathrm{~d}, J=2.3 \mathrm{~Hz}, 4 \mathrm{H})$. ${ }^{13} \mathrm{C}$ NMR $\left(101 \mathrm{MHz}\right.$, DMSO- $\left.d_{6}\right) \delta 170.52,169.00,148.00,140.64,133.42,130.71,128.66,126.57,123.60$, $119.92,118.72,114.15,42.85,30.14,16.35$.

$\mathrm{N}$-(4-(aminomethyl)phenyl)- $\mathrm{N}$-(4-chlorophenyl)cyclopropane-1,1-dicarboxamide(10D). Brown solid $(70 \%),{ }_{1}^{1} \mathrm{H}$ NMR $\left(400 \mathrm{MHz}, \mathrm{DMSO}-d_{6}\right) \delta 10.79(\mathrm{~s}, 1 \mathrm{H}), 8.27(\mathrm{~d}, J=5.9 \mathrm{~Hz}, 1 \mathrm{H}), 7.63(\mathrm{~d}, J=8.4 \mathrm{~Hz}, 2 \mathrm{H})$, $7.35(\mathrm{~d}, J=8.4 \mathrm{~Hz}, 2 \mathrm{H}), 6.93(\mathrm{~d}, J=8.0 \mathrm{~Hz}, 2 \mathrm{H}), 6.50(\mathrm{~d}, J=7.9 \mathrm{~Hz}, 2 \mathrm{H}), 4.96(\mathrm{~s}, 2 \mathrm{H}), 4.15(\mathrm{~d}, J=5.8 \mathrm{~Hz}$, $2 \mathrm{H}), 1.38(\mathrm{~d}, J=4.6 \mathrm{~Hz}, 4 \mathrm{H}) .{ }^{13} \mathrm{C}$ NMR $\left(101 \mathrm{MHz}, \mathrm{DMSO}-d_{6}\right) \delta 170.17,168.34,147.47,137.62,128.45$, $128.15,127.02,126.08,121.46,113.68,42.35,29.43,15.88$.

$\mathrm{N}$-(4-(aminomethyl)phenyl)- $\mathrm{N}$-(3-bromophenyl)cyclopropane-1,1-dicarboxamide (10E). Brown solid $(50 \%),{ }^{1} \mathrm{H}$ NMR $\left(400 \mathrm{MHz}\right.$, DMSO- $\left.d_{6}\right) \delta 10.80(\mathrm{~s}, 1 \mathrm{H}), 8.28(\mathrm{t}, J=5.8 \mathrm{~Hz}, 1 \mathrm{H}), 7.99(\mathrm{~s}, 1 \mathrm{H})$, $7.49(\mathrm{~d}, J=6.8 \mathrm{~Hz}, 1 \mathrm{H}), 7.25(\mathrm{~d}, J=6.5 \mathrm{~Hz}, 2 \mathrm{H}), 6.93(\mathrm{~d}, J=8.0 \mathrm{~Hz}, 2 \mathrm{H}), 6.50(\mathrm{~d}, J=7.9 \mathrm{~Hz}$, 2H), $4.96(\mathrm{~s}, 2 \mathrm{H}), 4.14(\mathrm{~d}, J=5.7 \mathrm{~Hz}, 2 \mathrm{H}), 1.37(\mathrm{~s}, 4 \mathrm{H}) .{ }^{13} \mathrm{C}$ NMR $\left(101 \mathrm{MHz}\right.$, DMSO- $\left.d_{6}\right) \delta 169.99,168.50$, $147.46,140.27,130.52,128.15,126.11,126.00,122.29,121.39,118.62,113.67,42.36,29.65,15.83$.

$\mathrm{N}$-(4-(aminomethyl)phenyl)-N-(4-bromophenyl)cyclopropane-1,1-dicarboxamide (10F). Brown solid $(55 \%),{ }^{1} \mathrm{H}$ NMR $\left(400 \mathrm{MHz}, \mathrm{DMSO}-d_{6}\right) \delta 10.80(\mathrm{~s}, 1 \mathrm{H}), 8.28(\mathrm{t}, J=5.8 \mathrm{~Hz}, 1 \mathrm{H}), 7.58(\mathrm{~d}, J=8.6 \mathrm{~Hz}, 2 \mathrm{H})$, $7.47(\mathrm{~d}, J=8.5 \mathrm{~Hz}, 2 \mathrm{H}), 6.93(\mathrm{~d}, J=7.9 \mathrm{~Hz}, 2 \mathrm{H}), 6.50(\mathrm{~d}, J=7.9 \mathrm{~Hz}, 2 \mathrm{H}), 4.95(\mathrm{~s}, 2 \mathrm{H}), 4.15(\mathrm{~d}, J=5.6 \mathrm{~Hz}, 2 \mathrm{H})$, $1.38(\mathrm{~d}, J=4.7 \mathrm{~Hz}, 4 \mathrm{H}) .{ }^{13} \mathrm{C}$ NMR $\left(101 \mathrm{MHz}, \mathrm{DMSO}-d_{6}\right) \delta 170.18,168.35,147.49,138.03,131.36,128.16$, $126.07,121.82,115.05,113.67,42.35,29.44,15.92$.

$\mathrm{N}$-(4-(aminomethyl)phenyl)-N-(3-methoxyphenyl)cyclopropane-1,1-dicarboxamide(10G). Brown solid $(71 \%),{ }_{1}^{1} \mathrm{H}$ NMR $\left(400 \mathrm{MHz}, \mathrm{DMSO}-d_{6}\right) \delta 10.76(\mathrm{~s}, 1 \mathrm{H}), 8.25(\mathrm{t}, J=5.9 \mathrm{~Hz}, 1 \mathrm{H}), 7.29(\mathrm{~s}, 1 \mathrm{H})$, $7.19(\mathrm{t}, J=8.1 \mathrm{~Hz}, 1 \mathrm{H}), 7.11(\mathrm{~d}, J=8.1 \mathrm{~Hz}, 1 \mathrm{H}), 6.92(\mathrm{~d}, J=8.0 \mathrm{~Hz}, 2 \mathrm{H}), 6.64(\mathrm{dd}, J=8.1,2.4 \mathrm{~Hz}, 1 \mathrm{H})$, $6.50(\mathrm{~d}, J=8.0 \mathrm{~Hz}, 2 \mathrm{H}), 4.98(\mathrm{~s}, 2 \mathrm{H}), 4.14(\mathrm{~d}, J=5.7 \mathrm{~Hz}, 2 \mathrm{H}), 3.72(\mathrm{~s}, 3 \mathrm{H}), 1.38(\mathrm{~d}, J=7.8 \mathrm{~Hz}, 4 \mathrm{H})$. ${ }^{13} \mathrm{C}$ NMR $\left(101 \mathrm{MHz}\right.$, DMSO- $\left.d_{6}\right) \delta 170.48,168.17,159.45,147.42,139.78,129.38,128.13,126.10,113.70$, $112.05,109.13,105.45,54.97,42.30,29.20,15.98$.

$\mathrm{N}$-(4-(aminomethyl)phenyl)-N-(4-methoxyphenyl)cyclopropane-1,1-dicarboxamide $\mathbf{( 1 0 H ) . ~ B r o w n ~ s o l i d ~}$ $(74 \%),{ }_{1}^{1} \mathrm{H}$ NMR $\left(400 \mathrm{MHz}, \mathrm{DMSO}-d_{6}\right) \delta 10.54(\mathrm{~s}, 1 \mathrm{H}), 8.36(\mathrm{t}, J=5.4 \mathrm{~Hz}, 1 \mathrm{H}), 7.48(\mathrm{~d}, J=8.6 \mathrm{~Hz}, 2 \mathrm{H})$, $6.93(\mathrm{~d}, J=8.0 \mathrm{~Hz}, 2 \mathrm{H}), 6.87(\mathrm{~d}, J=8.6 \mathrm{~Hz}, 2 \mathrm{H}), 6.50(\mathrm{~d}, J=8.0 \mathrm{~Hz}, 2 \mathrm{H}), 4.97(\mathrm{~s}, 2 \mathrm{H}), 4.14(\mathrm{~d}, J=5.7 \mathrm{~Hz}$, 2H), $3.71(\mathrm{~s}, 3 \mathrm{H}), 1.38(\mathrm{~d}, J=7.7 \mathrm{~Hz}, 4 \mathrm{H}) .{ }^{13} \mathrm{C}$ NMR $\left(101 \mathrm{MHz}, \mathrm{DMSO}-d_{6}\right) \delta 170.48,167.98,155.42,147.51$, $131.66,128.15,126.08,121.61,113.68,55.12,42.30,28.88,15.90$.

$\mathrm{N}$-(4-(aminomethyl)phenyl)-N-(m-tolyl)cyclopropane-1,1-dicarboxamide $\quad(\mathbf{1 0 I}) . \quad$ Brown solid $(62 \%),{ }_{1}^{1} \mathrm{H} \mathrm{NMR}\left(400 \mathrm{MHz}, \mathrm{DMSO}-d_{6}\right) \delta 10.73(\mathrm{~s}, 1 \mathrm{H}), 8.28(\mathrm{~s}, 1 \mathrm{H}), 7.49-7.25(\mathrm{~m}, 2 \mathrm{H}), 7.17(\mathrm{t}, J=7.7 \mathrm{~Hz}, 1 \mathrm{H})$, $6.51(\mathrm{~d}, J=7.9 \mathrm{~Hz}, 2 \mathrm{H}), 4.96(\mathrm{~s}, 2 \mathrm{H}), 4.15(\mathrm{~d}, J=5.7 \mathrm{~Hz}, 2 \mathrm{H}), 2.27(\mathrm{~s}, 3 \mathrm{H}), 1.40(\mathrm{~d}, J=8.3 \mathrm{~Hz}$, $4 \mathrm{H}) .{ }^{13} \mathrm{C}$ NMR $\left(101 \mathrm{MHz}\right.$, DMSO- $\left.d_{6}\right) \delta 170.59,168.12,147.51,138.47,137.85,128.46,128.16,126.06$, $124.19,120.41,117.01,113.69,42.32,28.97,21.07,16.07$.

$\mathrm{N}$-(4-(aminomethyl)phenyl)-N-(p-tolyl)cyclopropane-1,1-dicarboxamide (10J). Brown solid $(69 \%),{ }_{1}^{1} \mathrm{H}$ NMR $\left(400 \mathrm{MHz}, \mathrm{DMSO}-d_{6}\right) \delta 10.67(\mathrm{~s}, 1 \mathrm{H}), 8.29(\mathrm{~d}, J=5.9 \mathrm{~Hz}, 1 \mathrm{H}), 7.46(\mathrm{dd}, J=8.2,2.1 \mathrm{~Hz}, 2 \mathrm{H})$, $7.10(\mathrm{~d}, J=7.9 \mathrm{~Hz}, 2 \mathrm{H}), 6.94(\mathrm{~d}, J=7.8 \mathrm{~Hz}, 2 \mathrm{H}), 6.52(\mathrm{dd}, J=8.2,2.2 \mathrm{~Hz}, 2 \mathrm{H}), 4.97(\mathrm{~s}, 2 \mathrm{H})$, $4.16(\mathrm{~d}, J=5.5 \mathrm{~Hz}, 2 \mathrm{H}), 2.25(\mathrm{~s}, 3 \mathrm{H}), 1.40(\mathrm{dd}, J=10.4,2.7 \mathrm{~Hz}, 4 \mathrm{H}) .{ }^{13} \mathrm{C}$ NMR $\left(101 \mathrm{MHz}, \mathrm{DMSO}-d_{6}\right) \delta$ 170.56, 168.04, 147.48, 136.05, 132.45, 129.00, 128.16, 126.09, 119.92, 113.71, 42.32, 28.94, 20.41, 16.01 .

$\mathrm{N}$-(4-(aminomethyl)phenyl)- $\mathrm{N}$-(3-cyanophenyl)cyclopropane-1,1-dicarboxamide (10K). Brown solid $(59 \%),{ }_{1}^{1} \mathrm{H}$ NMR $\left(400 \mathrm{MHz}, \mathrm{DMSO}-d_{6}\right) \delta 10.94(\mathrm{~s}, 1 \mathrm{H}), 8.29(\mathrm{~s}, 1 \mathrm{H}), 8.13(\mathrm{~s}, 1 \mathrm{H}), 7.85-7.68(\mathrm{~m}, 1 \mathrm{H})$, $7.51(\mathrm{~d}, J=4.7 \mathrm{~Hz}, 2 \mathrm{H}), 6.92(\mathrm{~d}, J=7.8 \mathrm{~Hz}, 2 \mathrm{H}), 6.50(\mathrm{~d}, J=7.9 \mathrm{~Hz}, 2 \mathrm{H}), 4.98(\mathrm{~s}, 2 \mathrm{H}), 4.15(\mathrm{~d}, J=5.8 \mathrm{~Hz}$, 2H), 1.39 (s, 4H). ${ }^{13} \mathrm{C}$ NMR (101 MHz, DMSO- $\left.d_{6}\right) \delta 169.87,168.77,147.49,139.51,130.01,128.16,126.92$, $126.08,124.48,122.73,118.67,113.66,111.37,42.37,29.72,15.85$. 
N-(4-(aminomethyl)phenyl)-N-(4-cyanophenyl)cyclopropane-1,1-dicarboxamide (10L). Brown solid $(63 \%),{ }^{1} \mathrm{H}$ NMR $\left(400 \mathrm{MHz}, \mathrm{DMSO}-d_{6}\right) \delta 11.12(\mathrm{~s}, 1 \mathrm{H}), 8.29(\mathrm{~s}, 1 \mathrm{H}), 7.81(\mathrm{~d}, J=8.9 \mathrm{~Hz}, 2 \mathrm{H})$, $7.76(\mathrm{~d}, J=8.9 \mathrm{~Hz}, 2 \mathrm{H}), 6.93(\mathrm{~d}, J=8.4 \mathrm{~Hz}, 2 \mathrm{H}), 6.60-6.34(\mathrm{~m}, 2 \mathrm{H}), 5.01(\mathrm{~s}, 2 \mathrm{H}), 4.15(\mathrm{~d}, J=5.7 \mathrm{~Hz}, 2 \mathrm{H})$, $1.40(\mathrm{~s}, 4 \mathrm{H}) .{ }^{13} \mathrm{C}$ NMR $\left(101 \mathrm{MHz}, \mathrm{DMSO}-d_{6}\right) \delta 170.40,169.29,147.96,143.47,133.56,128.66,126.56$, $120.28,119.54,114.16,105.54,42.86,30.46,16.44$

N-(4-(aminomethyl)phenyl)-N-(3-(trifluoromethyl)phenyl)cyclopropane-1,1-dicarboxamide (10M). Brown solid (76\%), ${ }^{1} \mathrm{H}$ NMR (400 MHz, DMSO-d 6 ) $\delta 10.91(\mathrm{~s}, 1 \mathrm{H}), 8.31(\mathrm{t}, J=5.8 \mathrm{~Hz}, 1 \mathrm{H}), 8.15(\mathrm{~s}, 1 \mathrm{H})$, $7.79(\mathrm{~d}, J=8.2 \mathrm{~Hz}, 1 \mathrm{H}), 7.53(\mathrm{t}, J=8.0 \mathrm{~Hz}, 1 \mathrm{H}), 7.40(\mathrm{~d}, J=7.7 \mathrm{~Hz}, 1 \mathrm{H}), 6.93(\mathrm{~d}, J=7.9 \mathrm{~Hz}, 2 \mathrm{H})$, $6.50(\mathrm{~d}, J=7.9 \mathrm{~Hz}, 2 \mathrm{H}), 4.95(\mathrm{~s}, 2 \mathrm{H}), 4.16(\mathrm{~d}, J=5.6 \mathrm{~Hz}, 2 \mathrm{H}), 1.39(\mathrm{~d}, J=4.6 \mathrm{~Hz}, 4 \mathrm{H}) .{ }^{13} \mathrm{C} \mathrm{NMR}$ $\left(101 \mathrm{MHz}, \mathrm{DMSO}-d_{6}\right) \delta 169.87,168.74,147.49,139.51,129.71,129.30(\mathrm{~d}, J=31.7 \mathrm{~Hz}), 128.15,126.11$, $124.10(\mathrm{~d}, J=272.2 \mathrm{~Hz}), 123.41,119.68(\mathrm{~d}, J=3.8 \mathrm{~Hz}), 116.05(\mathrm{~d}, J=4.4 \mathrm{~Hz}), 113.65,42.38,29.80,15.75$.

$\mathrm{N}-(4-($ aminomethyl)phenyl)-N-(4-(trifluoromethyl)phenyl)cyclopropane-1,1-dicarboxamide $\quad(\mathbf{1 0 N})$. Brown solid (70\%), ${ }^{1} \mathrm{H}$ NMR (400 MHz, DMSO-d 6$) \delta 11.08(\mathrm{~s}, 1 \mathrm{H}), 8.28(\mathrm{~d}, J=5.9 \mathrm{~Hz}, 1 \mathrm{H})$, $7.83(\mathrm{~d}, J=8.4 \mathrm{~Hz}, 2 \mathrm{H}), 7.66(\mathrm{~d}, J=8.4 \mathrm{~Hz}, 2 \mathrm{H}), 6.93(\mathrm{~d}, J=7.9 \mathrm{~Hz}, 2 \mathrm{H}), 6.51(\mathrm{~d}, J=7.9 \mathrm{~Hz}, 2 \mathrm{H})$, $4.95(\mathrm{~s}, 2 \mathrm{H}), 4.16(\mathrm{~d}, J=5.6 \mathrm{~Hz}, 2 \mathrm{H}), 1.41(\mathrm{~d}, J=3.2 \mathrm{~Hz}, 4 \mathrm{H}) .{ }^{13} \mathrm{C}$ NMR $\left(101 \mathrm{MHz}, \mathrm{DMSO}-d_{6}\right) \delta 170.12$, $168.71,147.50,142.27,128.16,126.06,125.84(\mathrm{~d}, J=3.6 \mathrm{~Hz}), 124.62(\mathrm{~d}, J=213.2 \mathrm{~Hz}), 123.12(\mathrm{~d}, J=26.2 \mathrm{~Hz})$, $119.68,113.66,42.37,29.63,16.02$.

N-(4-(aminomethyl)phenyl)-N-phenylcyclopropane-1,1-dicarboxamide (100). Brown solid (78\%), ${ }^{1} \mathrm{H}$ NMR (400 MHz, DMSO-d 6 ) $\delta 10.75(\mathrm{~s}, 1 \mathrm{H}), 8.28(\mathrm{t}, J=5.9 \mathrm{~Hz}, 1 \mathrm{H}), 7.58(\mathrm{~d}, J=8.0 \mathrm{~Hz}, 2 \mathrm{H})$, $7.30(\mathrm{t}, J=7.8 \mathrm{~Hz}, 2 \mathrm{H}), 7.06(\mathrm{t}, J=7.4 \mathrm{~Hz}, 1 \mathrm{H}), 6.93(\mathrm{~d}, J=7.9 \mathrm{~Hz}, 2 \mathrm{H}), 6.51(\mathrm{~d}, J=7.9 \mathrm{~Hz}, 2 \mathrm{H}), 4.96(\mathrm{~s}, 2 \mathrm{H})$, $4.15(\mathrm{~d}, J=5.7 \mathrm{~Hz}, 2 \mathrm{H}), 1.40(\mathrm{~d}, J=8.7 \mathrm{~Hz}, 4 \mathrm{H}) .{ }^{13} \mathrm{C}$ NMR $\left(101 \mathrm{MHz}, \mathrm{DMSO}-\mathrm{d}_{6}\right) \delta 170.47,168.19,147.50$, $138.59,128.61,128.15,126.07,123.49,119.89,113.68,42.33,29.14,15.98$.

N-(4-(aminomethyl)phenyl)-N-(4-chloro-3-(trifluoromethyl)phenyl)cyclopropane-1,1-dicarboxamide (10P). Brown solid $(80 \%),{ }^{1} \mathrm{H}$ NMR $\left(400 \mathrm{MHz}, \mathrm{DMSO}-d_{6}\right) \delta 10.94(\mathrm{~s}, 1 \mathrm{H}), 8.31(\mathrm{t}, J=5.9 \mathrm{~Hz}, 1 \mathrm{H})$, $8.25(\mathrm{~d}, J=2.3 \mathrm{~Hz}, 1 \mathrm{H}), 7.85(\mathrm{dd}, J=8.8,2.3 \mathrm{~Hz}, 1 \mathrm{H}), 7.63(\mathrm{~d}, J=8.7 \mathrm{~Hz}, 1 \mathrm{H}), 6.93(\mathrm{~d}, J=7.9 \mathrm{~Hz}, 2 \mathrm{H})$, $6.50(\mathrm{~d}, J=7.9 \mathrm{~Hz}, 2 \mathrm{H}), 4.95(\mathrm{~s}, 2 \mathrm{H}), 4.15(\mathrm{~d}, J=5.7 \mathrm{~Hz}, 2 \mathrm{H}), 1.38(\mathrm{~s}, 4 \mathrm{H}) .{ }^{13} \mathrm{C} \mathrm{NMR}(101 \mathrm{MHz}$, DMSO- $\left.d_{6}\right) \delta 169.59,168.83,147.49,138.28,131.79,128.15,126.52(\mathrm{~d}, J=30.6 \mathrm{~Hz}), 126.09,124.62,123.99$, $122.73(\mathrm{~d}, J=272.8 \mathrm{~Hz}), 118.63(\mathrm{~d}, J=5.7 \mathrm{~Hz}), 113.64,42.39,30.03,15.65$.

\subsubsection{General Procedure for the Preparation of 12A-P}

To a suspension of 6-(2-chloro-5-fluoropyrimidin-4-yl)-1-isopropyl-1H-benzo[d](1,2,3)riazole (6) (583.4 mg, $2 \mathrm{mmol})$ in $20 \mathrm{~mL}$ 1,4-dioxane, the following compounds were added: 10A-P (2 mmol), $\mathrm{Pd}(\mathrm{OAc})_{2}(11 \mathrm{mg}, 0.05 \mathrm{mmol}), \mathrm{BINAP}(62 \mathrm{mg}, 0.1 \mathrm{mmol})$ and $\mathrm{Cs}_{2} \mathrm{CO}_{3}(978 \mathrm{mg}, 3 \mathrm{mmol})$ and the flask was purged with Ar. Then, the flask was sealed and the mixture was heated for $12 \mathrm{~h}$ at $100^{\circ} \mathrm{C}$. The reaction was cooled to RT, the solvent was removed under reduced pressure, and the residue was purified by silica gel column chromatography to obtain $\mathbf{1 2 A}-\mathbf{P}$.

N-(4-((5-fluoro-4-(1-isopropyl-1H-benzo[d](1,2,3)triazol-6-yl)pyrimidin-2-yl)amino)benzyl)-N-(3-fluo rophenyl)cyclopropane-1,1-dicarboxamide(12A). Light yellow solid; 43\% yield; $\mathrm{mp} 104.9{ }^{\circ} \mathrm{C}$. ${ }^{1} \mathrm{H}$ NMR (400 MHz, DMSO-d 6 ) $\delta 10.90(\mathrm{~s}, 1 \mathrm{H}), 9.85(\mathrm{~s}, 1 \mathrm{H}), 8.68(\mathrm{~d}, J=3.3 \mathrm{~Hz}, 1 \mathrm{H}), 8.51(\mathrm{~s}, 1 \mathrm{H})$, $8.44(\mathrm{t}, J=5.9 \mathrm{~Hz}, 1 \mathrm{H}), 8.21(\mathrm{~d}, J=8.8 \mathrm{~Hz}, 1 \mathrm{H}), 8.02(\mathrm{~d}, J=8.8 \mathrm{~Hz}, 1 \mathrm{H}), 7.74(\mathrm{~d}, J=8.5 \mathrm{~Hz}, 2 \mathrm{H})$, $7.63(\mathrm{~d}, J=11.5 \mathrm{~Hz}, 1 \mathrm{H}), 7.34-7.26(\mathrm{~m}, 2 \mathrm{H}), 7.22(\mathrm{~d}, J=8.4 \mathrm{~Hz}, 2 \mathrm{H}), 6.90-6.83(\mathrm{~m}, 1 \mathrm{H}), 5.31(\mathrm{p}$, $J=6.7 \mathrm{~Hz}, 1 \mathrm{H}), 4.29(\mathrm{~d}, J=5.7 \mathrm{~Hz}, 2 \mathrm{H}), 1.67(\mathrm{~d}, J=6.7 \mathrm{~Hz}, 6 \mathrm{H}), 1.41(\mathrm{~s}, 4 \mathrm{H}) .{ }^{13} \mathrm{C} \mathrm{NMR}(101 \mathrm{MHz}$, DMSO) $\delta 170.88,168.87,162.53(\mathrm{~d}, J=240.9 \mathrm{~Hz}), 156.97(\mathrm{~d}, J=2.7 \mathrm{~Hz}), 151.79,151.03(\mathrm{~d}, J=9.6 \mathrm{~Hz})$, $149.28,148.26(\mathrm{~d}, J=25.6 \mathrm{~Hz}), 146.63,140.93(\mathrm{~d}, J=11.0 \mathrm{~Hz}), 139.65,132.87,132.36,132.30,130.63$ $(\mathrm{d}, J=9.5 \mathrm{~Hz}), 127.95,124.69(\mathrm{~d}, J=5.6 \mathrm{~Hz}), 119.98,119.07,116.02(\mathrm{~d}, J=2.5 \mathrm{~Hz}), 112.23(\mathrm{~d}, J=6.6 \mathrm{~Hz})$, $110.34(\mathrm{~d}, J=21.1 \mathrm{~Hz}), 107.15(\mathrm{~d}, J=26.2 \mathrm{~Hz}), 51.76,42.75,30.17,22.47,16.44 .{ }^{19} \mathrm{~F} \mathrm{NMR}(376 \mathrm{MHz}$, DMSO-d 6 ) $\delta$-107.43(s, 1F), -145.82 (s, 1F). ESI-HRMS m/z calcd. for chemical formula: $\mathrm{C}_{31} \mathrm{H}_{29} \mathrm{~F}_{2} \mathrm{~N}_{8} \mathrm{O}_{2}{ }^{+}$ 583.2376, found 583.2367 [M + H] $]^{+}$. HPLC purity $99 \%$.

N-(4-((5-fluoro-4-(1-isopropyl-1H-benzo[d] $(1,2,3)$ triazol-6-yl)pyrimidin-2-yl)amino)benzyl)-N-(4-fluor ophenyl)cyclopropane-1,1-dicarboxamide (12B).Light yellow solid; 47\% yield; mp $109.5{ }^{\circ} \mathrm{C} .{ }^{1} \mathrm{H}$ NMR 
$\left(400 \mathrm{MHz}, \mathrm{DMSO}_{6} \mathrm{~d}_{6}\right) \delta 10.67(\mathrm{~s}, 1 \mathrm{H}), 9.84(\mathrm{~s}, 1 \mathrm{H}), 8.68(\mathrm{~d}, J=3.4 \mathrm{~Hz}, 1 \mathrm{H}), 8.51(\mathrm{~s}, 1 \mathrm{H}), 8.45(\mathrm{t}, J=5.9 \mathrm{~Hz}$, $1 \mathrm{H}), 8.22(\mathrm{~d}, J=8.8 \mathrm{~Hz}, 1 \mathrm{H}), 8.03(\mathrm{~d}, J=8.9 \mathrm{~Hz}, 1 \mathrm{H}), 7.76-7.72(\mathrm{~m}, 2 \mathrm{H}), 7.65-7.56(\mathrm{~m}, 2 \mathrm{H}), 7.22(\mathrm{~d}, J=8.3$ $\mathrm{Hz}, 2 \mathrm{H}), 7.12(\mathrm{t}, J=8.9 \mathrm{~Hz}, 2 \mathrm{H}), 5.32(\mathrm{p}, J=6.7 \mathrm{~Hz}, 1 \mathrm{H}), 4.29(\mathrm{~d}, J=5.8 \mathrm{~Hz}, 2 \mathrm{H}), 1.68(\mathrm{~d}, J=6.7 \mathrm{~Hz}, 6 \mathrm{H})$, $1.41(\mathrm{~d}, J=2.4 \mathrm{~Hz}, 4 \mathrm{H}) .{ }^{13} \mathrm{C}$ NMR $(101 \mathrm{MHz}, \mathrm{DMSO}) \delta 170.45,168.14,158.14(\mathrm{~d}, J=239.8 \mathrm{~Hz})$, $156.89-156.32(\mathrm{~m}), 151.30,150.54(\mathrm{~d}, J=8.7 \mathrm{~Hz}), 148.79,147.76(\mathrm{~d}, J=26.1 \mathrm{~Hz}), 146.14,139.15,135.02$ $(\mathrm{d}, J=2.1 \mathrm{~Hz}), 132.40,131.87,127.45,124.19(\mathrm{~d}, J=5.5 \mathrm{~Hz}), 121.80(\mathrm{~d}, J=7.7 \mathrm{~Hz}), 119.49,118.61$, $115.20,114.97,111.73(\mathrm{~d}, J=6.5 \mathrm{~Hz}), 51.27,42.25,29.38,21.97,15.85 .{ }^{19} \mathrm{~F}$ NMR $(376 \mathrm{MHz}$, DMSO-d 6 ) $\delta$ $-114.18(\mathrm{~s}, 1 \mathrm{~F}),-145.83$ (s, 1F). ESI-HRMS $m / z$ calcd. for chemical formula: $\mathrm{C}_{31} \mathrm{H}_{29} \mathrm{~F}_{2} \mathrm{~N}_{8} \mathrm{O}_{2}{ }^{+} 583.2376$, found $583.2377[\mathrm{M}+\mathrm{H}]^{+}$. HPLC purity $98 \%$.

$\mathrm{N}$-(3-chlorophenyl)-N-(4-((5-fluoro-4-(1-isopropyl-1H-benzo[d](1,2,3)triazol-6-yl)pyrimidin-2-yl)amino) benzyl)cyclopropane-1,1-dicarboxamide (12C). Light yellow solid; $56 \%$ yield; $\mathrm{mp}$ $119.4{ }^{\circ} \mathrm{C} .{ }^{1} \mathrm{H}$ NMR $\left(400 \mathrm{MHz}, \mathrm{DMSO}_{-} \mathrm{d}_{6}\right) \delta 10.83(\mathrm{~s}, 1 \mathrm{H}), 9.85(\mathrm{~s}, 1 \mathrm{H}), 8.68(\mathrm{~d}, J=3.4 \mathrm{~Hz}, 1 \mathrm{H})$, $8.51(\mathrm{~s}, 1 \mathrm{H}), 8.45(\mathrm{t}, J=5.9 \mathrm{~Hz}, 1 \mathrm{H}), 8.22(\mathrm{~d}, J=8.8 \mathrm{~Hz}, 1 \mathrm{H}), 8.02(\mathrm{~d}, J=8.8 \mathrm{~Hz}, 1 \mathrm{H}), 7.85(\mathrm{~s}$, $1 \mathrm{H}), 7.74(\mathrm{~d}, J=8.5 \mathrm{~Hz}, 2 \mathrm{H}), 7.46(\mathrm{~d}, J=8.3 \mathrm{~Hz}, 1 \mathrm{H}), 7.30(\mathrm{t}, J=8.1 \mathrm{~Hz}, 1 \mathrm{H}), 7.22(\mathrm{~d}, J=8.3$ $\mathrm{Hz}, 2 \mathrm{H}), 7.09(\mathrm{dd}, J=7.8,2.2 \mathrm{~Hz}, 1 \mathrm{H}), 5.32(\mathrm{p}, J=6.7 \mathrm{~Hz}, 1 \mathrm{H}), 4.29(\mathrm{~d}, J=5.7 \mathrm{~Hz}, 2 \mathrm{H}), 1.68(\mathrm{~d}$, $J=6.7 \mathrm{~Hz}, 6 \mathrm{H}), 1.40(\mathrm{~s}, 4 \mathrm{H}) .{ }^{13} \mathrm{C}$ NMR $(101 \mathrm{MHz}, \mathrm{DMSO}) \delta 170.75,168.92,157.07-156.90(\mathrm{~m}), 151.79$, $151.04(\mathrm{~d}, J=9.7 \mathrm{~Hz}), 149.28,148.26(\mathrm{~d}, J=26.1 \mathrm{~Hz}), 146.63,140.65,139.65,133.41,132.88,132.36,132.30$, $130.69,127.96,124.70(\mathrm{~d}, J=5.9 \mathrm{~Hz}), 123.60,119.99,119.92,119.07,118.71,112.23(\mathrm{~d}, J=6.6 \mathrm{~Hz}), 51.77$, 42.77, 30.26, 22.48, 16.38. ${ }^{19} \mathrm{~F}$ NMR (376 MHz, DMSO-d 6 ) $\delta-145.8$ (s, 1F). ESI-HRMS $m / z$ calcd. for chemical formula: $\mathrm{C}_{31} \mathrm{H}_{29} \mathrm{ClFN}_{8} \mathrm{O}_{2}{ }^{+} 599.2081$, found 599.2077 [M $\left.+\mathrm{H}\right]^{+}$. HPLC purity $99 \%$.

$\mathrm{N}$-(4-chlorophenyl)-N-(4-((5-fluoro-4-(1-isopropyl-1H-benzo[d](1,2,3)triazol-6-yl)pyrimidin-2-yl)amino) benzyl)cyclopropane-1,1-dicarboxamide (12D). Light yellow solid; 52\% yield; mp118 ${ }^{\circ} \mathrm{C} .{ }^{1} \mathrm{H}$ NMR $\left(400 \mathrm{MHz}, \mathrm{DMSO}-\mathrm{d}_{6}\right) \delta 10.79(\mathrm{~s}, 1 \mathrm{H}), 9.84(\mathrm{~s}, 1 \mathrm{H}), 8.67(\mathrm{~d}, J=3.4 \mathrm{~Hz}, 1 \mathrm{H}), 8.51-8.49(\mathrm{~m}, 1 \mathrm{H}), 8.44(\mathrm{t}, J=$ $5.9 \mathrm{~Hz}, 1 \mathrm{H}), 8.21(\mathrm{~d}, J=8.8 \mathrm{~Hz}, 1 \mathrm{H}), 8.02(\mathrm{~d}, J=8.8 \mathrm{~Hz}, 1 \mathrm{H}), 7.73(\mathrm{~d}, J=8.6 \mathrm{~Hz}, 2 \mathrm{H}), 7.63(\mathrm{~d}, J=8.9 \mathrm{~Hz}$, $2 \mathrm{H}), 7.32(\mathrm{~d}, J=8.9 \mathrm{~Hz}, 2 \mathrm{H}), 7.21(\mathrm{~d}, J=8.6 \mathrm{~Hz}, 2 \mathrm{H}), 5.31(\mathrm{p}, J=6.7 \mathrm{~Hz}, 1 \mathrm{H}), 4.28(\mathrm{~d}, J=5.8 \mathrm{~Hz}, 2 \mathrm{H})$, $1.67(\mathrm{~d}, J=6.7 \mathrm{~Hz}, 6 \mathrm{H}), 1.47-1.32(\mathrm{~m}, 4 \mathrm{H}) .{ }^{13} \mathrm{C}$ NMR $(101 \mathrm{MHz}, \mathrm{DMSO}) \delta 170.91,168.73,156.98(\mathrm{~d}, J=$ $2.4 \mathrm{~Hz}), 151.79,151.04(\mathrm{~d}, J=9.2 \mathrm{~Hz}), 149.28,148.25(\mathrm{~d}, J=25.5 \mathrm{~Hz}), 146.63,139.65,138.13,132.87$, 132.36, 132.30, 128.93, 127.96, 127.51, $124.70(\mathrm{~d}, J=6.0 \mathrm{~Hz}), 121.94,119.98,119.09,112.23(\mathrm{~d}, J=6.7 \mathrm{~Hz})$, $51.76,42.75,30.06,22.47,16.42 .{ }^{19} \mathrm{~F}$ NMR $\left(376 \mathrm{MHz}, \mathrm{DMSO}_{6}\right) \delta-145.81$ (s, 1F). ESI-HRMS $\mathrm{m} / z$ calcd. for chemical formula: $\mathrm{C}_{31} \mathrm{H}_{29} \mathrm{ClFN}_{8} \mathrm{O}_{2}{ }^{+} 599.2081$, found $599.2072[\mathrm{M}+\mathrm{H}]^{+}$. HPLC purity $96 \%$.

$\mathrm{N}$-(3-bromophenyl)-N-(4-((5-fluoro-4-(1-isopropyl-1H-benzo[d](1,2,3)triazol-6-yl)pyrimidin-2-yl)amino) benzyl)cyclopropane-1,1-dicarboxamide (12E). Light yellow solid; $44 \%$ yield; mp $114.6{ }^{\circ} \mathrm{C} .{ }^{1} \mathrm{H}$ NMR $\left(400 \mathrm{MHz}, \mathrm{DMSO}_{\mathrm{d}}\right) \delta 10.80(\mathrm{~s}, 1 \mathrm{H}), 9.85(\mathrm{~s}, 1 \mathrm{H}), 8.68(\mathrm{~d}, J=3.4 \mathrm{~Hz}, 1 \mathrm{H}), 8.51(\mathrm{~s}, 1 \mathrm{H}), 8.45(\mathrm{t}, J=5.9$ $\mathrm{Hz}, 1 \mathrm{H}), 8.22(\mathrm{~d}, J=8.8 \mathrm{~Hz}, 1 \mathrm{H}), 8.08-7.96(\mathrm{~m}, 2 \mathrm{H}), 7.74(\mathrm{~d}, J=8.4 \mathrm{~Hz}, 2 \mathrm{H}), 7.49(\mathrm{~d}, J=2.2 \mathrm{~Hz}, 1 \mathrm{H})$, $7.27-7.16(\mathrm{~m}, 4 \mathrm{H}), 5.32(\mathrm{p}, J=6.7 \mathrm{~Hz}, 1 \mathrm{H}), 4.29(\mathrm{~d}, J=5.8 \mathrm{~Hz}, 2 \mathrm{H}), 1.68(\mathrm{~d}, J=6.7 \mathrm{~Hz}, 6 \mathrm{H}), 1.40(\mathrm{~s}, 4 \mathrm{H})$. ${ }^{13} \mathrm{C}$ NMR (101 MHz, DMSO) $\delta 170.72,168.91,156.98(\mathrm{~d}, J=3.0 \mathrm{~Hz}), 151.79,151.03(\mathrm{~d}, J=9.3 \mathrm{~Hz})$, $149.28,148.26(\mathrm{~d}, J=25.9 \mathrm{~Hz}), 146.63,140.79,139.65,132.88,132.36,132.31,131.00,127.96,126.50,124.70$ $(\mathrm{d}, J=5.9 \mathrm{~Hz}), 122.78,121.88,119.99,119.10,119.08,112.23(\mathrm{~d}, J=6.7 \mathrm{~Hz}), 51.77,42.77,30.29,22.48$, 16.36. ${ }^{19} \mathrm{~F}$ NMR $\left(376 \mathrm{MHz}\right.$, DMSO-d $\left.\mathrm{d}_{6}\right) \delta-145.81(\mathrm{~s}, 1 \mathrm{~F})$. ESI-HRMS $\mathrm{m} / \mathrm{z}$ calcd. for chemical formula: $\mathrm{C}_{31} \mathrm{H}_{29} \mathrm{BrFN}_{8} \mathrm{O}_{2}{ }^{+} 643.1575$, found $643.1572[\mathrm{M}+\mathrm{H}]^{+}$. HPLC purity $97 \%$.

N-(4-bromophenyl)-N-(4-((5-fluoro-4-(1-isopropyl-1H-benzo[d](1,2,3)triazol-6-yl)pyrimidin-2-yl) amino)benzyl)cyclopropane-1,1-dicarboxamide (12F). Light yellow solid; $42 \%$ yield; $\mathrm{mp} 214{ }^{\circ} \mathrm{C}$. ${ }^{1} \mathrm{H}$ NMR $\left(400 \mathrm{MHz}, \mathrm{DMSO}_{6} \mathrm{~d}_{6}\right) 10.79(\mathrm{~s}, 1 \mathrm{H}), 9.84(\mathrm{~s}, 1 \mathrm{H}), 8.68(\mathrm{~d}, J=3.5 \mathrm{~Hz}, 1 \mathrm{H}), 8.51(\mathrm{~s}, 1 \mathrm{H})$, $8.44(\mathrm{t}, J=5.9 \mathrm{~Hz}, 1 \mathrm{H}), 8.22(\mathrm{~d}, J=8.7 \mathrm{~Hz}, 1 \mathrm{H}), 8.02(\mathrm{~d}, J=8.8 \mathrm{~Hz}, 1 \mathrm{H}), 7.74(\mathrm{~d}, J=8.2 \mathrm{~Hz}, 2 \mathrm{H})$, $7.58(\mathrm{~d}, J=9.0 \mathrm{~Hz}, 2 \mathrm{H}), 7.46(\mathrm{~d}, J=8.9 \mathrm{~Hz}, 2 \mathrm{H}), 7.21(\mathrm{~d}, J=8.3 \mathrm{~Hz}, 2 \mathrm{H}), 5.32(\mathrm{p}, J=6.8 \mathrm{~Hz}, 1 \mathrm{H})$, $4.29(\mathrm{~d}, J=5.7 \mathrm{~Hz}, 2 \mathrm{H}), 1.68(\mathrm{~d}, J=6.8 \mathrm{~Hz}, 6 \mathrm{H}), 1.41(\mathrm{~s}, 4 \mathrm{H}) .{ }^{13} \mathrm{C}$ NMR $(101 \mathrm{MHz}, \mathrm{DMSO}) \delta 170.40$, 168.25, $156.48(\mathrm{~d}, J=2.4 \mathrm{~Hz}), 151.30,150.56(\mathrm{~d}, J=9.4 \mathrm{~Hz}), 148.79,147.77(\mathrm{~d}, J=26.1 \mathrm{~Hz}), 146.13$, 139.15, 138.06, 132.37, 131.87, 131.81, 131.35, 127.46, 124.20 (d, J = 5.6 Hz), 121.81, 119.50, 118.60, 115.04, $111.74(\mathrm{~d}, J=6.8 \mathrm{~Hz}), 51.27,42.26,29.60,21.99,15.93 .{ }^{19} \mathrm{~F} \mathrm{NMR}\left(376 \mathrm{MHz}, \mathrm{DMSO}-\mathrm{d}_{6}\right) \delta-145.81(\mathrm{~s}, 1 \mathrm{~F})$. 
ESI-HRMS $m / z$ calcd. for chemical formula: $\mathrm{C}_{31} \mathrm{H}_{29} \mathrm{BrFN}_{8} \mathrm{O}_{2}{ }^{+} 643.1575$, found $643.1576[\mathrm{M}+\mathrm{H}]^{+}$. HPLC purity $95 \%$.

$\mathrm{N}$-(4-((5-fluoro-4-(1-isopropyl-1H-benzo[d](1,2,3)triazol-6-yl)pyrimidin-2-yl)amino)benzyl)-N-(3-methoxy phenyl)cyclopropane-1,1-dicarboxamide (12G).Light yellow solid; $47 \%$ yield; mp $101{ }^{\circ} \mathrm{C} .{ }^{1} \mathrm{H}$ NMR $\left(400 \mathrm{MHz}, \mathrm{DMSO}_{6} \mathrm{~d}_{6}\right) \delta 10.76(\mathrm{~s}, 1 \mathrm{H}), 9.84(\mathrm{~s}, 1 \mathrm{H}), 8.68(\mathrm{~d}, J=3.3 \mathrm{~Hz}, 1 \mathrm{H}), 8.51(\mathrm{~s}, 1 \mathrm{H}), 8.42(\mathrm{t}, J=5.9 \mathrm{~Hz}$, $1 \mathrm{H}), 8.22(\mathrm{~d}, J=8.9 \mathrm{~Hz}, 1 \mathrm{H}), 8.03(\mathrm{dd}, J=8.8,1.4 \mathrm{~Hz}, 1 \mathrm{H}), 7.81-7.64(\mathrm{~m}, 2 \mathrm{H}), 7.31(\mathrm{~d}, J=2.3 \mathrm{~Hz}, 1 \mathrm{H})$, $7.26-7.09(\mathrm{~m}, 4 \mathrm{H}), 6.63(\mathrm{ddd}, J=8.1,2.7,1.2 \mathrm{~Hz}, 1 \mathrm{H}), 5.32(\mathrm{p}, J=6.7 \mathrm{~Hz}, 1 \mathrm{H}), 4.29(\mathrm{~d}, J=5.7 \mathrm{~Hz}, 2 \mathrm{H})$, $3.71(\mathrm{~s}, 3 \mathrm{H}), 1.68(\mathrm{~d}, J=6.7 \mathrm{~Hz}, 6 \mathrm{H}), 1.42(\mathrm{~d}, J=3.9 \mathrm{~Hz}, 4 \mathrm{H}) .{ }^{13} \mathrm{C}$ NMR $(101 \mathrm{MHz}, \mathrm{DMSO}) \delta 170.71$, $168.08,159.44,156.48(\mathrm{~d}, J=2.3 \mathrm{~Hz}), 151.30,150.54(\mathrm{~d}, J=8.9 \mathrm{~Hz}), 148.79,147.76(\mathrm{~d}, J=25.8 \mathrm{~Hz}), 146.14$, $139.80,139.16,132.37,131.84(\mathrm{~d}, J=5.4 \mathrm{~Hz}), 129.36,128.12,127.44,124.19(\mathrm{~d}, J=5.6 \mathrm{~Hz}), 119.49,118.60$, $113.67,112.06,111.73(\mathrm{~d}, J=6.6 \mathrm{~Hz}), 109.10,105.49,54.95,51.28,42.23,29.33,21.97,16.03 .{ }^{19} \mathrm{~F} \mathrm{NMR}$ $\left(376 \mathrm{MHz}, \mathrm{DMSO}-\mathrm{d}_{6}\right) \delta-145.79(\mathrm{~s}, 1 \mathrm{~F})$. ESI-HRMS $\mathrm{m} / \mathrm{z}$ calcd. for chemical formula: $\mathrm{C}_{32} \mathrm{H}_{32} \mathrm{FN}_{8} \mathrm{O}_{3}{ }^{+}$ 595.2576 , found $595.2578[\mathrm{M}+\mathrm{H}]^{+}$. HPLC purity $99 \%$.

$\mathrm{N}$-(4-((5-fluoro-4-(1-isopropyl-1H-benzo[d](1,2,3)triazol-6-yl)pyrimidin-2-yl)amino)benzyl)-N-(4-methoxy phenyl)cyclopropane-1,1-dicarboxamide (12H). Light yellow solid; $55 \%$ yield; mp $181{ }^{\circ} \mathrm{C} .{ }^{1} \mathrm{H}$ NMR $\left.(400 \mathrm{MHz}, \text { DMSO-d })_{6}\right) \delta 10.50(\mathrm{~s}, 1 \mathrm{H}), 9.84(\mathrm{~s}, 1 \mathrm{H}), 8.68(\mathrm{~d}, J=3.3 \mathrm{~Hz}, 1 \mathrm{H}), 8.51(\mathrm{~s}, 1 \mathrm{H}), 8.47(\mathrm{t}, J=5.9 \mathrm{~Hz}$, $1 \mathrm{H}), 8.22(\mathrm{~d}, J=8.7 \mathrm{~Hz}, 1 \mathrm{H}), 8.03(\mathrm{~d}, J=8.8 \mathrm{~Hz}, 1 \mathrm{H}), 7.74(\mathrm{~d}, J=8.6 \mathrm{~Hz}, 2 \mathrm{H}), 7.49(\mathrm{~d}, J=9.0 \mathrm{~Hz}, 2 \mathrm{H})$, $7.22(\mathrm{~d}, J=8.6 \mathrm{~Hz}, 2 \mathrm{H}), 6.86(\mathrm{~d}, J=9.0 \mathrm{~Hz}, 2 \mathrm{H}), 5.31(\mathrm{p}, J=6.7 \mathrm{~Hz}, 1 \mathrm{H}), 4.29(\mathrm{~d}, J=6.0 \mathrm{~Hz}, 2 \mathrm{H}), 3.70(\mathrm{~s}$, $3 \mathrm{H}), 1.68(\mathrm{~d}, J=6.5 \mathrm{~Hz}, 6 \mathrm{H}), 1.40(\mathrm{~d}, J=6.4 \mathrm{~Hz}, 4 \mathrm{H}) .{ }^{13} \mathrm{C}$ NMR $(101 \mathrm{MHz}, \mathrm{DMSO}) \delta 170.68,167.84$, $156.48(\mathrm{~d}, J=2.4 \mathrm{~Hz}), 155.42,151.30,150.53(\mathrm{~d}, J=9.1 \mathrm{~Hz}), 148.79,147.78(\mathrm{~d}, J=25.9 \mathrm{~Hz}), 146.14,139.16$, $132.39,131.87,131.81,131.69,127.45,124.20(\mathrm{~d}, J=6.0 \mathrm{~Hz}), 121.59,119.49,118.61,113.67,111.73(\mathrm{~d}, J$ $=6.8 \mathrm{~Hz}), 55.10,51.28,42.23,29.04,21.97,15.90 .{ }^{19} \mathrm{~F}$ NMR $\left(376 \mathrm{MHz}, \mathrm{DMSO}-\mathrm{d}_{6}\right) \delta-145.79(\mathrm{~s}, 1 \mathrm{~F})$. ESI-HRMS $m / z$ calcd. for chemical formula: $\mathrm{C}_{32} \mathrm{H}_{32} \mathrm{FN}_{8} \mathrm{O}_{3}{ }^{+} 595.2576$, found $595.2576[\mathrm{M}+\mathrm{H}]^{+}$. HPLC purity $97 \%$.

$\mathrm{N}$-(4-((5-fluoro-4-(1-isopropyl-1H-benzo[d] $(1,2,3)$ triazol-6-yl)pyrimidin-2-yl)amino)benzyl)- $\mathrm{N}$-(m-tolyl) cyclopropane-1,1-dicarboxamide (12I). Light yellow solid; 61\% yield; mp $85{ }^{\circ} \mathrm{C} .{ }^{1} \mathrm{H}$ NMR $(400 \mathrm{MHz}$, DMSO-d $\left._{6}\right) \delta 10.72(\mathrm{~s}, 1 \mathrm{H}), 9.85(\mathrm{~s}, 1 \mathrm{H}), 8.68(\mathrm{~d}, J=3.4 \mathrm{~Hz}, 1 \mathrm{H}), 8.52(\mathrm{~s}, 1 \mathrm{H}), 8.44(\mathrm{t}, J=5.9 \mathrm{~Hz}, 1 \mathrm{H}), 8.22$ $(\mathrm{d}, J=8.8 \mathrm{~Hz}, 1 \mathrm{H}), 8.03(\mathrm{dt}, J=8.8,1.4 \mathrm{~Hz}, 1 \mathrm{H}), 7.83-7.72(\mathrm{~m}, 2 \mathrm{H}), 7.46-7.36(\mathrm{~m}, 2 \mathrm{H}), 7.22(\mathrm{~d}, J=8.5 \mathrm{~Hz}$, $2 \mathrm{H}), 7.16(\mathrm{t}, J=7.8 \mathrm{~Hz}, 1 \mathrm{H}), 6.86(\mathrm{~d}, J=7.5 \mathrm{~Hz}, 1 \mathrm{H}), 5.32(\mathrm{p}, J=6.7 \mathrm{~Hz}, 1 \mathrm{H}), 4.29(\mathrm{~d}, J=5.8 \mathrm{~Hz}, 2 \mathrm{H}), 2.25$ $(\mathrm{s}, 3 \mathrm{H}), 1.68(\mathrm{~d}, J=6.7 \mathrm{~Hz}, 6 \mathrm{H}), 1.42(\mathrm{~d}, J=3.8 \mathrm{~Hz}, 4 \mathrm{H}) .{ }^{13} \mathrm{C}$ NMR $(101 \mathrm{MHz}, \mathrm{DMSO}) \delta 171.31,168.52$, $156.98(\mathrm{~d}, J=2.1 \mathrm{~Hz}), 151.80,151.03(\mathrm{~d}, J=9.4 \mathrm{~Hz}), 149.29,148.27(\mathrm{~d}, J=25.8 \mathrm{~Hz}), 146.64,139.67,138.99$, 138.32, 132.86, 132.37, 132.32, 128.93, 127.95, 124.70 (d, J = $5.3 \mathrm{~Hz}), 120.90,119.99,119.10,117.50,112.23$ $(\mathrm{d}, J=6.6 \mathrm{~Hz}), 51.77,42.73,29.60,22.46,21.55,16.60 .{ }^{19} \mathrm{~F}$ NMR $\left(376 \mathrm{MHz}, \mathrm{DMSO}-\mathrm{d}_{6}\right) \delta-145.81(\mathrm{~s}, 1 \mathrm{~F})$. ESI-HRMS $m / z$ calcd. for chemical formula: $\mathrm{C}_{32} \mathrm{H}_{32} \mathrm{FN}_{8} \mathrm{O}_{2}{ }^{+} 579.2627$, found $579.2626[\mathrm{M}+\mathrm{H}]^{+}$. HPLC purity $98 \%$.

$N$-(4-((5-fluoro-4-(1-isopropyl-1H-benzo[d](1,2,3)triazol-6-yl)pyrimidin-2-yl)amino)benzyl)-N-(p-tolyl) cyclopropane-1,1-dicarboxamide (12J). Light yellow solid; 57\% yield; mp $190{ }^{\circ} \mathrm{C} .{ }^{1} \mathrm{H}$ NMR $(400 \mathrm{MHz}$, DMSO-d $\left._{6}\right) \delta 10.65(\mathrm{~s}, 1 \mathrm{H}), 9.84(\mathrm{~s}, 1 \mathrm{H}), 8.67(\mathrm{~d}, J=3.3 \mathrm{~Hz}, 1 \mathrm{H}), 8.51(\mathrm{~s}, 1 \mathrm{H}), 8.45(\mathrm{t}, J=5.9 \mathrm{~Hz}, 1 \mathrm{H}), 8.21$ $(\mathrm{d}, J=8.8 \mathrm{~Hz}, 1 \mathrm{H}), 8.02(\mathrm{~d}, J=8.8 \mathrm{~Hz}, 1 \mathrm{H}), 7.75(\mathrm{~d}, J=8.3 \mathrm{~Hz}, 2 \mathrm{H}), 7.46(\mathrm{~d}, J=8.1 \mathrm{~Hz}, 2 \mathrm{H}), 7.22(\mathrm{~d}, J=$ $8.3 \mathrm{~Hz}, 2 \mathrm{H}), 7.07(\mathrm{~d}, J=8.1 \mathrm{~Hz}, 2 \mathrm{H}), 5.31(\mathrm{p}, J=6.7 \mathrm{~Hz}, 1 \mathrm{H}), 4.29(\mathrm{~d}, J=5.8 \mathrm{~Hz}, 2 \mathrm{H}), 2.22(\mathrm{~s}, 3 \mathrm{H}), 1.67$ $(\mathrm{d}, J=6.7 \mathrm{~Hz}, 6 \mathrm{H}), 1.48-1.33(\mathrm{~m}, 4 \mathrm{H}) .{ }^{13} \mathrm{C}$ NMR $(101 \mathrm{MHz}, \mathrm{DMSO}) \delta 171.29,168.44,156.98(\mathrm{~d}, J=2.8$ $\mathrm{Hz}), 151.80,150.99(\mathrm{~d}, J=8.7 \mathrm{~Hz}), 149.29,148.26(\mathrm{~d}, J=25.8 \mathrm{~Hz}), 146.64,139.67,136.56,132.93,132.86$, 132.36, 132.32, 129.46, 127.94, 124.69 (d, J = 5.8 Hz), 120.41, 119.98, 119.11, 112.21 (d, J = 6.6 Hz), 51.77, $42.73,29.56,22.46,20.88,16.54 .{ }^{19} \mathrm{~F}$ NMR $\left(376 \mathrm{MHz}, \mathrm{DMSO}_{6}\right) \delta-145.76$ (s, 1F). ESI-HRMS $m / z$ calcd. for chemical formula: $\mathrm{C}_{32} \mathrm{H}_{32} \mathrm{FN}_{8} \mathrm{O}_{2}{ }^{+} 579.2627$, found $579.2623[\mathrm{M}+\mathrm{H}]^{+}$. HPLC purity $95 \%$.

$\mathrm{N}$-(3-cyanophenyl)-N-(4-((5-fluoro-4-(1-isopropyl-1H-benzo[d](1,2,3)triazol-6-yl)pyrimidin-2-yl)amino) benzyl)cyclopropane-1,1-dicarboxamide (12K). Light yellow solid; $63 \%$ yield; mp $108.4{ }^{\circ} \mathrm{C} .{ }^{1} \mathrm{H}$ NMR $\left(400 \mathrm{MHz}, \mathrm{DMSO}_{6}\right) \delta 10.94(\mathrm{~s}, 1 \mathrm{H}), 9.84(\mathrm{~s}, 1 \mathrm{H}), 8.67(\mathrm{~d}, J=3.3 \mathrm{~Hz}, 1 \mathrm{H}), 8.51(\mathrm{~s}, 1 \mathrm{H}), 8.46(\mathrm{t}, J=5.9 \mathrm{~Hz}$, $1 \mathrm{H}), 8.21(\mathrm{~d}, J=8.8 \mathrm{~Hz}, 1 \mathrm{H}), 8.14(\mathrm{~s}, 1 \mathrm{H}), 8.02(\mathrm{~d}, J=8.8 \mathrm{~Hz}, 1 \mathrm{H}), 7.83(\mathrm{ddd}, J=5.2,4.1,2.2 \mathrm{~Hz}, 1 \mathrm{H}), 7.74$ $(\mathrm{d}, J=8.6 \mathrm{~Hz}, 2 \mathrm{H}), 7.53-7.47(\mathrm{~m}, 2 \mathrm{H}), 7.21(\mathrm{~d}, J=8.6 \mathrm{~Hz}, 2 \mathrm{H}), 5.32(\mathrm{p}, J=6.7 \mathrm{~Hz}, 1 \mathrm{H}), 4.29(\mathrm{~d}, J=5.8 \mathrm{~Hz}$, 
2H), $1.68(\mathrm{~d}, J=6.7 \mathrm{~Hz}, 6 \mathrm{H}), 1.41(\mathrm{~s}, 4 \mathrm{H}) .{ }^{13} \mathrm{C} \mathrm{NMR}(101 \mathrm{MHz}, \mathrm{DMSO}) \delta 170.59,169.18,156.97(\mathrm{~d}, J=$ $2.2 \mathrm{~Hz}), 151.79,151.05(\mathrm{~d}, J=9.4 \mathrm{~Hz}), 149.28,148.25(\mathrm{~d}, J=26.1 \mathrm{~Hz}), 146.63,140.02,139.65,132.87$, 132.36, 132.30, 130.50, 127.96, 127.42, 124.96, 124.70 (d, J = 5.9 Hz), 123.21, 119.99, 119.15, 119.08, 112.23 $(\mathrm{d}, J=7.0 \mathrm{~Hz}), 111.86,51.76,42.78,30.37,22.48,16.36 .{ }^{19} \mathrm{~F}$ NMR $\left(376 \mathrm{MHz}, \mathrm{DMSO}-\mathrm{d}_{6}\right) \delta-145.81(\mathrm{~s}, 1 \mathrm{~F})$. ESI-HRMS $\mathrm{m} / z$ calcd. for chemical formula: $\mathrm{C}_{32} \mathrm{H}_{29} \mathrm{FN}_{9} \mathrm{O}_{2}{ }^{+} 590.2423$, found $590.2418[\mathrm{M}+\mathrm{H}]^{+}$. HPLC purity $99 \%$.

$\mathrm{N}$-(4-cyanophenyl)-N-(4-((5-fluoro-4-(1-isopropyl-1H-benzo[d](1,2,3)triazol-6-yl)pyrimidin-2-yl)amino) benzyl)cyclopropane-1,1-dicarboxamide (12L). Light yellow solid; 59\% yield; mp $241{ }^{\circ} \mathrm{C} .{ }^{1} \mathrm{H}$ NMR $\left(400 \mathrm{MHz}, \mathrm{DMSO}_{\mathrm{d}}\right) \delta 11.10(\mathrm{~s}, 1 \mathrm{H}), 9.83(\mathrm{~s}, 1 \mathrm{H}), 8.67(\mathrm{~d}, J=3.4 \mathrm{~Hz}, 1 \mathrm{H}), 8.51(\mathrm{~s}, 1 \mathrm{H}), 8.43(\mathrm{t}, J=5.9 \mathrm{~Hz}$, $1 \mathrm{H}), 8.21(\mathrm{~d}, J=8.8 \mathrm{~Hz}, 1 \mathrm{H}), 8.02(\mathrm{~d}, J=8.9 \mathrm{~Hz}, 1 \mathrm{H}), 7.81(\mathrm{~d}, J=8.9 \mathrm{~Hz}, 2 \mathrm{H}), 7.77-7.71(\mathrm{~m}, 4 \mathrm{H}), 7.21(\mathrm{~d}, J$ $=8.6 \mathrm{~Hz}, 2 \mathrm{H}), 5.32(\mathrm{p}, J=6.7 \mathrm{~Hz}, 1 \mathrm{H}), 4.29(\mathrm{~d}, J=5.7 \mathrm{~Hz}, 2 \mathrm{H}), 1.68(\mathrm{~d}, J=6.7 \mathrm{~Hz}, 6 \mathrm{H}), 1.42(\mathrm{~s}, 4 \mathrm{H}) .{ }^{13} \mathrm{C}$ NMR (101 MHz, DMSO) $\delta 170.64,169.21,156.98(\mathrm{~d}, J=2.3 \mathrm{~Hz}), 151.80,151.05(\mathrm{~d}, J=9.4 \mathrm{~Hz}), 149.29$, $148.24(\mathrm{~d}, J=25.6 \mathrm{~Hz}), 146.63,143.47,139.65,133.54,132.85,132.36,132.30,127.96,124.69$ (d, J = 6.0 Hz), 120.30, 119.99, 119.50, 119.09, $112.23(\mathrm{~d}, J=6.6 \mathrm{~Hz}), 105.57,51.77,42.78,30.57,22.48,16.46 .{ }^{19} \mathrm{~F} \mathrm{NMR}$ $\left(376 \mathrm{MHz}, \mathrm{DMSO}-\mathrm{d}_{6}\right) \delta-145.82(\mathrm{~s}, 1 \mathrm{~F})$. ESI-HRMS $\mathrm{m} / \mathrm{z}$ calcd. for chemical formula: $\mathrm{C}_{32} \mathrm{H}_{29} \mathrm{FN}_{9} \mathrm{O}_{2}{ }^{+}$ 590.2423 , found $590.2420[\mathrm{M}+\mathrm{H}]^{+}$. HPLC purity $96 \%$.

$\mathrm{N}$-(4-((5-fluoro-4-(1-isopropyl-1H-benzo[d](1,2,3)triazol-6-yl)pyrimidin-2-yl)amino)

benzyl)-N-(3-(trifluoromethyl)phenyl)cyclopropane-1,1-dicarboxamide (12M). Light yellow solid; $46 \%$ yield; mp $189{ }^{\circ} \mathrm{C} .{ }^{1} \mathrm{H}$ NMR $\left(400 \mathrm{MHz}, \mathrm{DMSO}_{6} \mathrm{~d}_{6}\right) \delta 10.90(\mathrm{~s}, 1 \mathrm{H}), 9.84(\mathrm{~s}, 1 \mathrm{H}), 8.68(\mathrm{~d}, J=3.4 \mathrm{~Hz}$, $1 \mathrm{H}), 8.51(\mathrm{~d}, J=1.3 \mathrm{~Hz}, 1 \mathrm{H}), 8.47(\mathrm{t}, J=5.9 \mathrm{~Hz}, 1 \mathrm{H}), 8.22(\mathrm{~d}, J=8.8 \mathrm{~Hz}, 1 \mathrm{H}), 8.15(\mathrm{~s}, 1 \mathrm{H}), 8.02(\mathrm{~d}, J=8.9$ $\mathrm{Hz}, 1 \mathrm{H}), 7.79(\mathrm{~d}, J=8.4 \mathrm{~Hz}, 1 \mathrm{H}), 7.74(\mathrm{~d}, J=8.6 \mathrm{~Hz}, 2 \mathrm{H}), 7.52(\mathrm{t}, J=8.0 \mathrm{~Hz}, 1 \mathrm{H}), 7.39(\mathrm{~d}, J=7.6 \mathrm{~Hz}, 1 \mathrm{H})$, $7.22(\mathrm{~d}, J=8.7 \mathrm{~Hz}, 2 \mathrm{H}), 5.32(\mathrm{p}, J=6.7 \mathrm{~Hz}, 1 \mathrm{H}), 4.30(\mathrm{~d}, J=5.8 \mathrm{~Hz}, 2 \mathrm{H}), 1.68(\mathrm{~d}, J=6.7 \mathrm{~Hz}, 6 \mathrm{H}), 1.41(\mathrm{~d}$, $J=1.9 \mathrm{~Hz}, 4 \mathrm{H}) .{ }^{13} \mathrm{C}$ NMR $(101 \mathrm{MHz}, \mathrm{DMSO}) \delta 170.58,169.16,156.99(\mathrm{~d}, J=2.7 \mathrm{~Hz}), 151.79,151.06(\mathrm{~d}, J$ $=9.1 \mathrm{~Hz}), 149.29,148.25(\mathrm{~d}, J=25.3 \mathrm{~Hz}), 146.64,140.02,139.65,132.91,132.36,132.32,130.21,129.78(\mathrm{~d}$, $J=31.4 \mathrm{~Hz}), 127.96,125.95,124.69(\mathrm{~d}, J=6.0 \mathrm{~Hz}), 123.91,120.20(\mathrm{~d}, J=4.2 \mathrm{~Hz}), 119.99,119.09,116.58(\mathrm{~d}$, $J=7.1 \mathrm{~Hz}), 112.23(\mathrm{~d}, J=6.6 \mathrm{~Hz}), 51.76,42.79,30.44,22.46,16.27 .{ }^{19} \mathrm{~F} \mathrm{NMR}\left(376 \mathrm{MHz}, \mathrm{DMSO}_{6}\right) \delta$ $-56.5(\mathrm{~s}, 3 \mathrm{~F}),-145.86(\mathrm{~s}, 1 \mathrm{~F})$. ESI-HRMS $\mathrm{m} / \mathrm{z}$ calcd. for chemical formula: $\mathrm{C}_{32} \mathrm{H}_{29} \mathrm{~F}_{4} \mathrm{~N}_{8} \mathrm{O}_{2}{ }^{+}$633.2344, found $633.2347[\mathrm{M}+\mathrm{H}]^{+}$. HPLC purity $99 \%$.

$\mathrm{N}$-(4-((5-fluoro-4-(1-isopropyl-1H-benzo[d](1,2,3)triazol-6-yl)pyrimidin-2-yl)amino)benzyl)-N-(4-(trifluor omethyl)phenyl)cyclopropane-1,1-dicarboxamide (12N). Light yellow solid; $48 \%$ yield; mp $219{ }^{\circ} \mathrm{C} .{ }^{1} \mathrm{H}$ NMR $\left(400 \mathrm{MHz}, \mathrm{DMSO}-\mathrm{d}_{6}\right) \delta 11.06(\mathrm{~s}, 1 \mathrm{H}), 9.84(\mathrm{~s}, 1 \mathrm{H}), 8.68(\mathrm{~d}, J=3.3 \mathrm{~Hz}, 1 \mathrm{H}), 8.51(\mathrm{~d}, J=1.3 \mathrm{~Hz}, 1 \mathrm{H}), 8.44$ $(\mathrm{t}, J=5.8 \mathrm{~Hz}, 1 \mathrm{H}), 8.22(\mathrm{dd}, J=8.7,0.8 \mathrm{~Hz}, 1 \mathrm{H}), 8.02(\mathrm{dt}, J=8.8,1.3 \mathrm{~Hz}, 1 \mathrm{H}), 7.83(\mathrm{~d}, J=8.4 \mathrm{~Hz}, 2 \mathrm{H})$, $7.78-7.71(\mathrm{~m}, 2 \mathrm{H}), 7.64(\mathrm{~d}, J=8.6 \mathrm{~Hz}, 2 \mathrm{H}), 7.26-7.17(\mathrm{~m}, 2 \mathrm{H}), 5.32(\mathrm{p}, J=6.7 \mathrm{~Hz}, 1 \mathrm{H}), 4.29(\mathrm{~d}, J=5.8$ $\mathrm{Hz}, 2 \mathrm{H}), 1.68(\mathrm{~d}, J=6.7 \mathrm{~Hz}, 6 \mathrm{H}), 1.43(\mathrm{~s}, 4 \mathrm{H}) .{ }^{13} \mathrm{C}$ NMR (101 MHz, DMSO) $\delta 170.82,169.11,156.99$ $(\mathrm{d}, J=2.6 \mathrm{~Hz}), 151.79,151.06(\mathrm{~d}, J=9.7 \mathrm{~Hz}), 149.29,148.25(\mathrm{~d}, J=25.6 \mathrm{~Hz}), 146.64,142.78,139.66,132.86$, 132.36, 132.30, 127.96, $126.34(\mathrm{~d}, J=4.5 \mathrm{~Hz}), 126.17,124.69(\mathrm{~d}, J=6.0 \mathrm{~Hz}), 124.12-123.42(\mathrm{~m}), 120.19$, $119.99,119.09,112.23(\mathrm{~d}, J=6.6 \mathrm{~Hz}), 51.76,42.77,30.30,22.47,16.51 .{ }^{19} \mathrm{~F}$ NMR $\left(376 \mathrm{MHz}, \mathrm{DMSO}_{-} \mathrm{d}_{6}\right) \delta$ $-55.52(\mathrm{~s}, 3 \mathrm{~F}),-145.85(\mathrm{~s}, 1 \mathrm{~F})$. ESI-HRMS $\mathrm{m} / z$ calcd. for chemical formula: $\mathrm{C}_{32} \mathrm{H}_{29} \mathrm{~F}_{4} \mathrm{~N}_{8} \mathrm{O}_{2}{ }^{+} 633.2344$, found $633.2343[\mathrm{M}+\mathrm{H}]^{+}$. HPLC purity $98 \%$.

$N$-(4-((5-fluoro-4-(1-isopropyl-1H-benzo[d] (1,2,3)triazol-6-yl)pyrimidin-2-yl)amino)benzyl)-N-phenylcy clopropane-1,1-dicarboxamide (12O). Light yellow solid; $41 \%$ yield; mp $103{ }^{\circ} \mathrm{C} .{ }^{1} \mathrm{H}$ NMR $(400 \mathrm{MHz}$, DMSO-d $\left._{6}\right) \delta 10.74(\mathrm{~s}, 1 \mathrm{H}), 9.85(\mathrm{~s}, 1 \mathrm{H}), 8.68(\mathrm{dd}, J=3.4,1.0 \mathrm{~Hz}, 1 \mathrm{H}), 8.51(\mathrm{~d}, J=1.3 \mathrm{~Hz}, 1 \mathrm{H})$, $8.44(\mathrm{t}, J=5.9 \mathrm{~Hz}, 1 \mathrm{H}), 8.22(\mathrm{~d}, J=8.8 \mathrm{~Hz}, 1 \mathrm{H}), 8.02(\mathrm{dt}, J=8.8,1.3 \mathrm{~Hz}, 1 \mathrm{H}), 7.84-7.71(\mathrm{~m}, 2 \mathrm{H}), 7.65-7.54$ $(\mathrm{m}, 2 \mathrm{H}), 7.28(\mathrm{dd}, J=8.5,7.3 \mathrm{~Hz}, 2 \mathrm{H}), 7.24-7.18(\mathrm{~m}, 2 \mathrm{H}), 7.09-6.97(\mathrm{~m}, 1 \mathrm{H}), 5.31(\mathrm{p}, J=6.7 \mathrm{~Hz}, 1 \mathrm{H})$, $4.29(\mathrm{~d}, J=5.8 \mathrm{~Hz}, 2 \mathrm{H}), 1.67(\mathrm{~d}, J=6.7 \mathrm{~Hz}, 6 \mathrm{H}), 1.45-1.35(\mathrm{~m}, 4 \mathrm{H}) .{ }^{13} \mathrm{C}$ NMR $(101 \mathrm{MHz}, \mathrm{DMSO}) \delta$ 171.20, 168.59, $156.98(\mathrm{~d}, J=2.0 \mathrm{~Hz}), 151.79,151.03(\mathrm{~d}, J=9.8 \mathrm{~Hz}), 149.28,148.28(\mathrm{~d}, J=26.2 \mathrm{~Hz}), 146.63$, 139.65, 139.11, 132.87, 132.36, 132.31, 129.08, 127.95, 124.70 (d, J = 5.8 Hz), 123.98, 120.38, 119.99, 119.09, $112.24(\mathrm{~d}, J=6.3 \mathrm{~Hz}), 51.77,42.73,29.77,22.47,16.52 .{ }^{19} \mathrm{~F}$ NMR $\left(376 \mathrm{MHz}, \mathrm{DMSO}-\mathrm{d}_{6}\right) \delta-145.81(\mathrm{~s}, 1 \mathrm{~F})$. ESI-HRMS $\mathrm{m} / z$ calcd. for chemical formula: $\mathrm{C}_{31} \mathrm{H}_{30} \mathrm{FN}_{8} \mathrm{O}_{2}{ }^{+} 565.2470$, found $565.2468[\mathrm{M}+\mathrm{H}]^{+}$. HPLC purity $99 \%$. 
N-(4-chloro-3-(trifluoromethyl)phenyl)-N-(4-((5-fluoro-4-(1-isopropyl-1H-benzo[d](1,2,3)triazol-6-yl) pyrimidin-2-yl)amino)benzyl)cyclopropane-1,1-dicarboxamide (12P). Light yellow solid; $44 \%$ yield; $\mathrm{mp}$ 108. ${ }^{\circ} \mathrm{C} .{ }^{1} \mathrm{H}$ NMR $\left(400 \mathrm{MHz}, \mathrm{DMSO}_{\mathrm{d}}\right) \delta 10.93(\mathrm{~s}, 1 \mathrm{H}), 9.84(\mathrm{~s}, 1 \mathrm{H}), 8.67(\mathrm{~d}, J=3.3 \mathrm{~Hz}, 1 \mathrm{H}), 8.51(\mathrm{~d}, J=$ $1.3 \mathrm{~Hz}, 1 \mathrm{H}), 8.48(\mathrm{t}, J=5.9 \mathrm{~Hz}, 1 \mathrm{H}), 8.25(\mathrm{~d}, J=2.6 \mathrm{~Hz}, 1 \mathrm{H}), 8.22(\mathrm{dd}, J=8.8,0.7 \mathrm{~Hz}, 1 \mathrm{H}), 8.02(\mathrm{dt}, J=8.8$, $1.4 \mathrm{~Hz}, 1 \mathrm{H}), 7.85(\mathrm{dd}, J=8.8,2.6 \mathrm{~Hz}, 1 \mathrm{H}), 7.73(\mathrm{~d}, J=8.6 \mathrm{~Hz}, 2 \mathrm{H}), 7.62(\mathrm{~d}, J=8.8 \mathrm{~Hz}, 1 \mathrm{H}), 7.21(\mathrm{~d}, J=8.6$ $\mathrm{Hz}, 2 \mathrm{H}), 5.32(\mathrm{p}, J=6.7 \mathrm{~Hz}, 1 \mathrm{H}), 4.29(\mathrm{~d}, J=5.8 \mathrm{~Hz}, 2 \mathrm{H}), 1.68(\mathrm{~d}, J=6.7 \mathrm{~Hz}, 6 \mathrm{H}), 1.40(\mathrm{~s}, 4 \mathrm{H}) .{ }^{13} \mathrm{C} \mathrm{NMR}$ $(101 \mathrm{MHz}, \mathrm{DMSO}) \delta 170.29,169.23,156.97(\mathrm{~d}, J=2.2 \mathrm{~Hz}), 151.79,151.06(\mathrm{~d}, J=8.3 \mathrm{~Hz}), 149.28,148.24(\mathrm{~d}$, $J=26.2 \mathrm{~Hz}), 146.63,139.65,138.80,132.89,132.36,132.30,127.97,126.99(\mathrm{~d}, J=31.0 \mathrm{~Hz}), 125.11,124.68$ $(\mathrm{d}, J=5.8 \mathrm{~Hz}), 124.53(\mathrm{~d}, J=8.3 \mathrm{~Hz}), 121.85,119.98,119.14,119.07,112.22(\mathrm{~d}, J=6.3 \mathrm{~Hz}), 51.76,42.80$, 30.69, 22.47, 16.15. ${ }^{19} \mathrm{~F}$ NMR (376 MHz, DMSO-d 6 ) $\delta-56.74(\mathrm{~s}, 3 \mathrm{~F}),-145.88(\mathrm{~s}, 1 \mathrm{~F})$. ESI-HRMS m/z calcd. for chemical formula: $\mathrm{C}_{32} \mathrm{H}_{28} \mathrm{ClF}_{4} \mathrm{~N}_{8} \mathrm{O}_{2}{ }^{+} 667.1954$, found $667.1953[\mathrm{M}+\mathrm{H}]^{+}$. HPLC purity $96 \%$.

\subsection{Biology}

\subsubsection{Molecular Docking}

All the calculations were carried out using the platform of Discovery Studio 3.1 (DS 3.1, Accelrys Inc., San Diego, CA). The receptor protein was prepared by the DS 3.1 software package. Docking studies were finished by Discovery Studio 3.1 to explore the predicted binding modes of compound 120 in CDK2 (PDB entry: 1H1P), CDK5 (PDB entry: 1UNG), CDK9 (PDB entry: 4BCF), respectively. Hydrogen atoms were added to proteins using Discovery Studio 3.1. The images were created by PyMOL.

\subsubsection{Kinase Inhibition Assays}

Kinase inhibition profiles were determined using KinaseProfiler services provided by Eurofins, and ATP concentrations used are the $\mathrm{Km}$ of corresponding kinases.

CDK1/cyclinB (h) (CDK2/cyclinA (h), CDK3/cyclinE (h), CDK4/CyclinD(h), CDK5/p25 (h), CDK6/cyclinD3 (h)) were incubated with $8 \mathrm{mM}$ MOPS pH 7.0, $0.2 \mathrm{mM}$ EDTA, $0.1 \mathrm{mg} / \mathrm{mL}$ histone H1, $10 \mathrm{mM} \mathrm{MgAcetate}$ and [gamma-33P]-ATP (specific activity and concentration as required).

CDK7/cyclinH/MAT1 (h) was incubated with 8 mM MOPS pH 7.0, 0.2 mM EDTA, 500 uM peptide, $10 \mathrm{mM} \mathrm{MgAcetate}$ and [gamma-33P]-ATP (specific activity and concentration as required).

CDK9/cyclinT1 (h) was incubated with $8 \mathrm{mM}$ MOPS pH 7.0, $0.2 \mathrm{mM}$ EDTA, $100 \mathrm{uM}$ KTFCGTPEYLAPEVRREPRILSEEEQEMFRDFDYIADWC, $10 \mathrm{mM} \mathrm{MgAcetate} \mathrm{and} \mathrm{[gamma-33P]-ATP}$ (specific activity and concentration as required).

Flt1 (h) was incubated with 8 mM MOPS pH 7.0, 0.2 mM EDTA, 250 uM KKKSPGEYVNIEFG, $10 \mathrm{mM} \mathrm{MgAcetate}$ and [g- 33P]-ATP; Flt3 (h) [Abl (h)] was incubated with $8 \mathrm{mM}$ MOPS pH 7.0, $0.2 \mathrm{mM}$ EDTA, 50 uM EAIYAAPFAKKK, 10 mM MgAcetate and [gamma-33P]- ATP; Flt4 (h) was incubated with $8 \mathrm{mM}$ MOPS pH 7.0, 0.2 mM EDTA, 500 uM GGEEEEYFELVKKKK, $10 \mathrm{mM} \mathrm{MgAcetate}$ and [gamma-33P]-ATP.

c-Kit (h) was incubated with $8 \mathrm{mM}$ MOPS pH 7.0, $0.2 \mathrm{mM}$ EDTA, $10 \mathrm{mM} \mathrm{MnCl} 2,0.1 \mathrm{mg} / \mathrm{mL}$ poly(Glu, Tyr) 4:1, $10 \mathrm{mM} \mathrm{MgAcetate} \mathrm{and} \mathrm{[gamma-33P]-ATP.}$

FGFR1 (h) was incubated with 8 mM MOPS pH 7.0, 0.2 mM EDTA, 250 uM KKKSPGEYVNIEFG, $10 \mathrm{mM} \mathrm{MgAcetate}$ and [gamma-33P]-ATP.

Src (1-530) (h) was incubated with $8 \mathrm{mM}$ MOPS pH 7.0, $0.2 \mathrm{mM}$ EDTA, $500 \mathrm{uM}$ GGEEEEYFELVKKKK, $10 \mathrm{mM}$ MgAcetate and [gamma-33P]-ATP.

KDR (h) was incubated with $8 \mathrm{mM}$ MOPS pH 7.0, $0.2 \mathrm{mM}$ EDTA, $0.33 \mathrm{mg} / \mathrm{mL}$ myelin basic protein, $10 \mathrm{mM} \mathrm{MgAcetate}$ and [gamma-33P]-ATP.

PDGFR-alfa(h) [PDGFR-beta(h)] was incubated with $8 \mathrm{mM}$ MOPS pH 7.0, $0.2 \mathrm{mMEDTA}, 0.1 \mathrm{mg} / \mathrm{mL}$ poly(Glu, Tyr) 4:1, $10 \mathrm{mM} \mathrm{MnCl2,10} \mathrm{mM} \mathrm{MgAcetate} \mathrm{and} \mathrm{[gamma-33P]-ATP.}$

All the reactions above were initiated by the addition of the Mg/ATP mix. After incubation for $40 \mathrm{~min}$ at room temperature, the reaction was stopped by the addition of phosphoric acid to a 
concentration of $0.5 \%$. An amount of $10 \mu \mathrm{L}$ of the reaction was then spotted onto a P30 filtermat and washed four times for $4 \mathrm{~min}$ in $0.425 \%$ phosphoric acid and once in methanol prior to drying and scintillation counting.

\subsubsection{Cytotoxicity Assay}

The viability of cells as determined using the CCK8 assay method. Cells were seeded (2000-3000 cells per well) in 96-well plates. After incubation for $24 \mathrm{~h}$ in serum-containing media, the cells were treated with drugs at different concentrations diluted with culture medium for $72 \mathrm{~h}$ at $37^{\circ} \mathrm{C}$ with a $5 \% \mathrm{CO}_{2}$ atmosphere. Then, $10 \mu \mathrm{L} \mathrm{CCK8}$ regent (Promega, WI) was added to each well, and the plates were incubated for $1-4 \mathrm{~h}$ at $37^{\circ} \mathrm{C}$. Finally, absorbance values of test wells ( $\mathrm{A}_{\mathrm{S}}$ ), control wells $\left(A_{C}\right)$ and blank wells $\left(A_{b}\right)$ at $450 \mathrm{~nm}$ were read using the Microplate Reader (Promega, WI). Inhibition ratios were calculated as follows: $\left[\left(A_{C}-A_{S}\right) /\left(A_{C}-A_{b}\right)\right] \times 100 \%$. $I_{50}$ values were calculated using GraphPad software [23].

\subsubsection{Cell Cycle Assay}

Cells were plated on 6-well culture plates at a density of $5 \times 10^{5}$ cells $/ \mathrm{mL}$. The cells were treated with the indicated concentrations of $\mathbf{1 2 O}$ or ribociclib for $24 \mathrm{~h}$ after their adherence. Cells were washed with PBS for three times and then fixed with ice cold $75 \%$ ethanol overnight. The fixed cells were then washed with PBS and stained with propidium iodide $(50 \mathrm{mg} / \mathrm{mL})$ in the presence of RNase A $(0.5 \mathrm{mg})$ for $30 \mathrm{~min}$ at $37^{\circ} \mathrm{C}$. The stained cells were then subjected to flow cytometry (Becton Dickinson (BD), San Jose, CA, USA.) for cell cycle analysis.

\subsubsection{Annexin V-FITC/ PI Apoptosis Assay}

Cells at a density of $3 \times 10^{5}$ cells/mL were seeded in 6-well plates and treated with compounds at different concentrations for $48 \mathrm{~h}$. The cells were then harvested and washed twice with cold PBS. Then, the cells were subjected to an Annexin V/PI Apoptosis Detection kit (BD Biosciences) for staining according to manufacturer's instructions, and finally analyzed by flow cytometry (Modfit, BD).

\subsubsection{Colony Formation Assay}

Cells treated with indicated compounds or vehicle were washed with PBS, trypsinized, and reseeded into 6-well plates at 500-1000 cells per well. The colonies were allowed to form for 10-15 days. At the end of the culture, cells were washed with PBS, fixed with methanol for 30 min, then stained with $0.5 \%$ crystal violet overnight. After careful washing, the images were taken.

\subsubsection{In Vivo Assay}

All animal studies were conducted under the approval of the Experimental Animal Management Committee of Nankai University (No. NKUEC20190228). Six- to eight-week-old female BALB/c nude mice were purchased from Beijing HFK Bioscience Company. Mice were fed in an SPF-level laboratory animal room. The mice were kept in independent ventilation cages with autoclaved corncobs at the bottom of the cage as bedding. The dimensions of the cages were $390 \times 180 \times 180 \mathrm{~mm}$. Environmental factors: Average air temperature ranged from 20 to $26^{\circ} \mathrm{C}$ with average relative air humidity ranging from 40 to $70 \%$. Noise was below 60 decibels. Ventilation times were more than 15 times/hour. Air velocity was $0.1 \sim 0.2 \mathrm{~m} / \mathrm{s}$. The ammonia concentration was below $14 /\left(\mathrm{mg} / \mathrm{m}^{3}\right)$. Working illumination was 150 300LX and animal illumination was 15 20LX. The nutritional components of mouse food include: water content: $\leq 10 \%$, crude protein: $\geq 18 \%$, crude fat: $\geq 4 \%$, crude fiber: $\geq 5 \%$, minerals: $\geq 4 \%$, calcium: $1.0-1.8 \%$, Phosphorus: $0.6-1.2 \%$. The water that mice drink is sterilized by the animal drinking system.

Cells SiHa were harvested during the exponential-growth phase, washed 3 times with serum-free medium, followed by resuspension at a concentration of $2 \times 10^{6}$ per mL. A total of $100 \mu \mathrm{L}$ of 
cell suspension was injected into SCID mice subcutaneously. After the tumors had grown to 100-150 $\mathrm{mm}^{3}$, all the mice were randomized into 5 groups (5 mice for each group, 25 mice total). The mice were treated daily via oral gavage administration with $\mathbf{1 2 O}\left(5,10\right.$, or $\left.20 \mathrm{mg} \mathrm{kg}^{-1} \mathrm{~d}^{-1}\right)$, cisplatin (20 mg kg-1 $\mathrm{d}^{-1}$ ), or vehicle. The dosage adopted in our experiment concurred with the previous literature $[21,25]$ and showed prominent antitumor efficacy. Mice were monitored for side effects every day. Body weights and tumor sizes were determined every other day and volume was also observed. At the end-point of the study, all mice had survived. Mice were euthanized and the subcutaneous tumor tissues were stripped and collected. Tumor measurements were calculated using a digital vernier caliper, and the volumes were determined using the following calculation: (short $\left.{ }^{2}\right)$ $\times$ long $\times 0.5$. Inhibition rate of tumor growth was calculated using the following formula: $100 \times\{1$ - [(tumor volume final-tumor volume initial) for 120-treated group]/ [(tumor volume final-tumor volume initial) for the vehicle-treated group]\} [23].

\subsubsection{Hematoxylin and Eosin (H\&E)}

H\&E staining was performed on the formalin-fixed, paraffin-embedded orthotopic mice tumor tissues. Tumor tissue sections were deparaffinized, counterstained with hematoxylin and eosin, then observed under a light microscopy (Olympus).

\subsubsection{Statistical Analysis}

Statistical analysis results were analyzed values by GraphPad Prism software (GradPad Systems Inc., San Diego, CA). For Student $t$ test and ANOVA $p<0.05$ was considered statistically significant. Values were expressed as means \pm SEM. Significance was determined by $\chi^{2}$ test, others were determined by Student's t-test. A value of $p<0.05$ was used as the criterion for statistical significance. ${ }^{* * *}$ indicates significant difference with $p<0.001,{ }^{* *}$ indicates $p<0.01, *$ indicates $p<0.05$.

\section{Conclusions}

In summary, we have described the discovery of $\mathbf{1 2 0}$ as potent a novel multi-target kinase inhibitor with $\mathrm{IC}_{50}$ value in the nanomolar range against solid tumor. Docking evaluations provided insight into enzyme inhibitory interactions of $\mathbf{1 2 0}$ and explained that the introduction of triazole moiety was a key strategic group in the improvement of CDK inhibitory activities and antiproliferative activities. Compound $\mathbf{1 2 O}$ displayed an outstanding inhibition against several kinases considered important regulators of cancer progression. In cellular assays, $\mathbf{1 2 O}$ exhibited excellent cytotoxicity and anti-proliferative activity on various cancer cell lines. In addition, $\mathbf{1 2 O}$ arrested the cell cycle in the G2 phase. Furthermore, the anticancer activity of $\mathbf{1 2 O}$ was also associated with inducing apoptosis. In in vivo pharmacology evaluations of compound $\mathbf{1 2 O}$ showed significant antitumor activity (TGI $=79.29 \%$ ) in an SiHa xenograft model at the dose of $20 \mathrm{mg} / \mathrm{kg}$. These findings implied that molecule $\mathbf{1 2 0}$ deserves further research.

Supplementary Materials: The following are available online, Figure S1: Strategy of designing novel inhibitors. Figure S2: The inhibition curve of $12 \mathrm{O}$ against CDKs and FLTs. Figure S3. $12 \mathrm{O}$ effectively inhibited the proliferation of SKOV3 cells as determined by colony formation assay. Figure S4: ${ }^{1} \mathrm{H}$ and ${ }^{13} \mathrm{C}$ spectra of compound 12A. Figure S5: ${ }^{1} \mathrm{H}$ and ${ }^{13} \mathrm{C}$ spectra of compound 12B. Figure S6: ${ }^{1} \mathrm{H}$ and ${ }^{13} \mathrm{C}$ spectra of compound $12 \mathrm{C}$. Figure S7: ${ }^{1} \mathrm{H}$ and ${ }^{13} \mathrm{C}$ spectra of compound 12D. Figure S8: ${ }^{1} \mathrm{H}$ and ${ }^{13} \mathrm{C}$ spectra of compound 12E. Figure S9: ${ }^{1} \mathrm{H}$ and ${ }^{13} \mathrm{C}$ spectra of compound 12F. Figure S10: ${ }^{1} \mathrm{H}$ and ${ }^{13} \mathrm{C}$ spectra of compound $12 \mathrm{G}$. Figure S11: ${ }^{1} \mathrm{H}$ and ${ }^{13} \mathrm{C}$ spectra of compound 12H. Figure S12: ${ }^{1} \mathrm{H}$ and ${ }^{13} \mathrm{C}$ spectra of compound 12I. Figure S13: ${ }^{1} \mathrm{H}$ and ${ }^{13} \mathrm{C}$ spectra of compound 12J. Figure S14: ${ }^{1} \mathrm{H}$ and ${ }^{13} \mathrm{C}$ spectra of compound $12 \mathrm{~K}$. Figure S15: ${ }^{1} \mathrm{H}$ and ${ }^{13} \mathrm{C}$ spectra of compound 12L. Figure S16: ${ }^{1} \mathrm{H}$ and ${ }^{13} \mathrm{C}$ spectra of compound $12 \mathrm{M}$. Figure S17: ${ }^{1} \mathrm{H}$ and ${ }^{13} \mathrm{C}$ spectra of compound $12 \mathrm{~N}$. Figure S18: ${ }^{1} \mathrm{H}$ and ${ }^{13} \mathrm{C}$ spectra of compound 12O. Figure S19: ${ }^{1} \mathrm{H}$ and ${ }^{13} \mathrm{C}$ spectra of compound 12P.

Author Contributions: Y.F. oversaw the overall project and acquired funding; Z.H. synthesized the compounds and analysis the data; Y.F. and X.W. performed biological screening; Z.H. and Y.M. performed data analysis; Y.F. and Y.L. wrote the paper. Z.H. and Y.L. designed the compounds; S.Y. administrated the project; Y.S. reviewed the paper. All authors have read and agreed to the published version of the manuscript. 
Funding: This research was funded by the National Natural Science Foundation of China (81903099), the National Key Research and Development Program of China (2018YFE0114300) and the National Natural Science Foundation of China (81972882).

Conflicts of Interest: The authors declare no conflict of interest.

\section{References}

1. Matta, A.; Ralhan, R. Overview of current and future biologically based targeted therapies in head and neck squamous cell carcinoma. Head Neck Oncol. 2009, 1, 6. [CrossRef] [PubMed]

2. Wu, P.; Nielsen, T.E.; Clausen, M.H. Small-molecule kinase inhibitors: An analysis of FDA-approved drugs. Drug Discov. Today 2016, 21, 5-10. [CrossRef] [PubMed]

3. Wu, P.; Nielsen, T.E.; Clausen, M.H. FDA-approved small-molecule kinase inhibitors. Trends Pharmacol. Sci. 2015, 36, 422-439. [CrossRef] [PubMed]

4. Baker, S.J.; Reddy, E.P. Targeted inhibition of kinases in cancer therapy. Mt. Sinai J. Med. A J. Transl. Pers. Med. 2010, 77, 573-586. [CrossRef]

5. Zimmermann, G.R.; Lehar, J.; Keith, C.T. Multi-target therapeutics: When the whole is greater than the sum of the parts. Drug Discov. Today 2007, 12, 34-42. [CrossRef]

6. Sams-Dodd, F. Target-based drug discovery: Is something wrong? Drug Discov. Today 2005, 10, $139-147$. [CrossRef]

7. Chen, J.B.; Chern, T.R.; Wei, T.T.; Chen, C.C.; Lin, J.H.; Fang, J.M. Design and synthesis of dual-action inhibitors targeting histone deacetylases and 3-hydroxy-3-methylglutaryl coenzyme A reductase for cancer treatment. J. Med. Chem. 2013, 56, 3645-3655. [CrossRef] [PubMed]

8. Qi, B.; Yang, Y.; Gong, G.; He, H.; Yue, X.; Xu, X.; Hu, Y.; Li, J.; Chen, T.; Wan, X.; et al. Discovery of N(1)-(4-((7-(3-(4-ethylpiperazin-1-yl)propoxy)-6-methoxyquinolin-4-yl)oxy)-3,5-di fluorophenyl)-N(3)-(2-(2,6-difluorophenyl)-4-oxothiazolidin-3-yl)urea as a multi-tyrosine kinase inhibitor for drug-sensitive and drug-resistant cancers treatment. Eur. J. Med. Chem. 2019, 163, 10-27.

9. Ravez, S.; Barczyk, A.; Six, P.; Cagnon, A.; Garofalo, A.; Goossens, L.; Depreux, P. Inhibition of tumor cell growth and angiogenesis by 7-aminoalkoxy-4-aryloxy-quinazoline ureas, a novel series of multi-tyrosine kinase inhibitors. Eur. J. Med. Chem. 2014, 79, 369-381. [CrossRef] [PubMed]

10. Chen, R.; Chen, B. The role of dasatinib in the management of chronic myeloid leukemia. Drug Des. Dev. Ther. 2015, 9, 773-779. [CrossRef]

11. Roskoski, R., Jr. Cyclin-dependent protein serine/threonine kinase inhibitors as anticancer drugs. Pharmacol. Res. 2019, 139, 471-488. [CrossRef]

12. Oner, M.; Lin, E.; Chen, M.C.; Hsu, F.N.; Shazzad Hossain Prince, G.M.; Chiu, K.Y.; Teng, C.J.; Yang, T.Y.; Wang, H.Y.; Yue, C.H.; et al. Future Aspects of CDK5 in Prostate Cancer: From Pathogenesis to Therapeutic Implications. Int. J. Mol. Sci. 2019, 20, 3881. [CrossRef]

13. Asghar, U.; Witkiewicz, A.K.; Turner, N.C.; Knudsen, E.S. The history and future of targeting cyclin-dependent kinases in cancer therapy. Nat. Rev. Drug Discov. 2015, 14, 130-146. [CrossRef]

14. Whittaker, S.R.; Mallinger, A.; Workman, P.; Clarke, P.A. Inhibitors of cyclin-dependent kinases as cancer therapeutics. Pharmacol. Ther. 2017, 173, 83-105. [CrossRef] [PubMed]

15. O’Leary, B.; Finn, R.S.; Turner, N.C. Treating cancer with selective CDK4/6 inhibitors. Nat. Rev. Clin. Oncol. 2016, 13, 417-430. [CrossRef]

16. Ribociclib Approved for Advanced Breast Cancer. Cancer Discov. 2017, 7, OF3. [CrossRef]

17. Kim, E.S. Abemaciclib: First Global Approval. Drugs 2017, 77, 2063-2070. [CrossRef]

18. Hortobagyi, G.N.; Stemmer, S.M.; Burris, H.A.; Yap, Y.S.; Sonke, G.S.; Paluch-Shimon, S.; Campone, M.; Blackwell, K.L.; Andre, F.; Winer, E.P.; et al. Ribociclib as First-Line Therapy for HR-Positive, Advanced Breast Cancer. N. Engl. J. Med. 2016, 375, 1738-1748. [CrossRef]

19. Munster, P.N.; Hamilton, E.P.; Estevez, L.G.; De Boer, R.H.; Mayer, I.A.; Campone, M.; Asano, S.; Bhansali, S.; Zhang, V.; Hewes, B.; et al. Ph IB study of LEE011 and BYL719 in combination with letrozole in ER+, Her2-breast cancer. J. Clin. Oncol. 2014, 32, 143. [CrossRef] 
20. Hafner, M.; Mills, C.E.; Subramanian, K.; Chen, C.; Chung, M.; Boswell, S.A.; Everley, R.A.; Liu, C.; Walmsley, C.S.; Juric, D.; et al. Multiomics Profiling Establishes the Polypharmacology of FDA-Approved CDK4/6 Inhibitors and the Potential for Differential Clinical Activity. Cell Chem. Biol. 2019, 26, 1067-1080.e8. [CrossRef]

21. Goh, K.C.; Novotny-Diermayr, V.; Hart, S.; Ong, L.C.; Loh, Y.K.; Cheong, A.; Tan, Y.C.; Hu, C.; Jayaraman, R.; William, A.D.; et al. TG02, a novel oral multi-kinase inhibitor of CDKs, JAK2 and FLT3 with potent anti-leukemic properties. Leukemia 2012, 26, 236-243. [CrossRef] [PubMed]

22. Wang, X.; Deng, K.; Wang, C.; Li, Y.; Wang, T.; Huang, Z.; Ma, Y.; Sun, P.; Shi, Y.; Yang, S.; et al. Novel CDKs inhibitors for the treatment of solid tumour by simultaneously regulating the cell cycle and transcription control. J. Enzym. Inhib. Med. Chem. 2020, 35, 414-423. [CrossRef]

23. Li, Y.; Luo, X.; Guo, Q.; Nie, Y.; Wang, T.; Zhang, C.; Huang, Z.; Wang, X.; Liu, Y.; Chen, Y.; et al. Discovery of N1-(4-((7-Cyclopentyl-6-(dimethylcarbamoyl)-7 H-pyrrolo[2,3- d]pyrimidin-2-yl)amino)phenyl)N8-hydroxyoctanediamide as a Novel Inhibitor Targeting Cyclin-dependent Kinase 4/9 (CDK4/9) and Histone Deacetlyase1 (HDAC1) against Malignant Cancer. J. Med. Chem. 2018, 61, 3166-3192. [CrossRef]

24. Xu, Z.; Zhao, S.J.; Liu, Y. 1,2,3-Triazole-containing hybrids as potential anticancer agents: Current developments, action mechanisms and structure-activity relationships. Eur. J. Med. Chem. 2019, 183, 111700. [CrossRef]

25. Huang, Z.; Zhao, B.; Qin, Z.; Li, Y.; Wang, T.; Zhou, W.; Zheng, J.; Yang, S.; Shi, Y.; Fan, Y.; et al. Novel dual inhibitors targeting CDK4 and VEGFR2 synergistically suppressed cancer progression and angiogenesis. Eur. J. Med. Chem. 2019, 181, 111541. [CrossRef]

26. Tadesse, S.; Caldon, E.C.; Tilley, W.; Wang, S. Cyclin-Dependent Kinase 2 Inhibitors in Cancer Therapy: An Update. J. Med. Chem. 2019, 62, 4233-4251. [CrossRef]

27. Sonawane, Y.A.; Taylor, M.A.; Napoleon, J.V.; Rana, S.; Contreras, J.I.; Natarajan, A. Cyclin Dependent Kinase 9 Inhibitors for Cancer Therapy. J. Med. Chem. 2016, 59, 8667-8684. [CrossRef] [PubMed]

28. Nathanson, S.D. Insights into the mechanisms of lymph node metastasis. Cancer 2003, 98, 413-423. [CrossRef]

29. Yu, H.; Zhang, S.; Zhang, R.; Zhang, L. The role of VEGF-C/D and Flt-4 in the lymphatic metastasis of early-stage invasive cervical carcinoma. J. Exp. Clin. Cancer Res. CR 2009, 28, 98. [CrossRef]

30. Xu, Y.; Lin, H.; Meng, N.; Lu, W.; Li, G.; Han, Y.; Dai, X.; Xia, Y.; Song, X.; Yang, S.; et al. YL529, a novel, orally available multikinase inhibitor, potently inhibits angiogenesis and tumour growth in preclinical models. Br. J. Pharmacol. 2013, 169, 1766-1780. [CrossRef]

31. Fletcher, G.C.; Brokx, R.D.; Denny, T.A.; Hembrough, T.A.; Plum, S.M.; Fogler, W.E.; Sidor, C.F.; Bray, M.R. ENMD-2076 is an orally active kinase inhibitor with antiangiogenic and antiproliferative mechanisms of action. Mol. Cancer Ther. 2011, 10, 126-137. [CrossRef]

32. Kolinsky, K.; Tovar, C.; Zhang, Y.E.; Railkar, A.; Yang, H.; Carvajal, D.; Nevins, T.; Geng, W.; Linn, M.; Packman, K.; et al. Preclinical evaluation of the novel multi-targeted agent R1530. Cancer Chemother. Pharmacol. 2011, 68, 1585-1594. [CrossRef] [PubMed]

33. Fousteris, M.A.; Papakyriakou, A.; Koutsourea, A.; Manioudaki, M.; Lampropoulou, E.; Papadimitriou, E.; Spyroulias, G.A.; Nikolaropoulos, S.S. Pyrrolo[2,3-a]carbazoles as potential cyclin dependent kinase 1 (CDK1) Inhibitors. Synthesis, biological evaluation, and binding mode through docking simulations. J. Med. Chem. 2008, 51, 1048-1052. [CrossRef]

34. Mapelli, M.; Massimiliano, L.; Crovace, C.; Seeliger, M.A.; Tsai, L.H.; Meijer, L.; Musacchio, A. Mechanism of CDK5/p25 binding by CDK inhibitors. J. Med. Chem. 2005, 48, 671-679. [CrossRef] [PubMed]

Sample Availability: Samples of the compounds $\mathbf{1 2 O}$ are available from the authors.

Publisher's Note: MDPI stays neutral with regard to jurisdictional claims in published maps and institutional affiliations.

(C) 2020 by the authors. Licensee MDPI, Basel, Switzerland. This article is an open access article distributed under the terms and conditions of the Creative Commons Attribution (CC BY) license (http://creativecommons.org/licenses/by/4.0/). 